Revista Española de Antropología Americana

ISSN: 0556-6533

https://dx.doi.org/10.5209/reaa.75963

\title{
Creando el mundo, creando el discurso: similitudes entre los códices Borgia y Vindobonensis
}

\author{
Katarzyna Mikulska ${ }^{1}$ y Manuel A. Hermann Lejarazu²
}

Recibido: 31 de mayo de 2019 / Aceptado: 25 de junio de 2020

Resumen. El objetivo de este artículo es mostrar ciertos episodios paralelos presentes en la parte central del Códice Borgia y en el lado anverso del Códice Vindobonensis, así como semejanzas en la construcción del discurso gráfico en estos dos manuscritos prehispánicos. Ambos documentos encabezan "grupos" de códices denominados, cada uno por su parte, "Grupo Borgia" y "Grupo Vindobonensis", el primer conjunto comprendiendo los llamados "códices prescriptivos" (de función adivinatoria), y el segundo "códices descriptivos" (de contenido histórico). Esta marcada diferencia se desvanece, si realizamos una comparación entre algunas escenas significativas que se encuentran en el lado anverso del Códice Vindobonensis y en la parte central del Códice Borgia. En concreto, nos referimos a las páginas en las que se relatan sucesos relacionados con la creación del mundo y de diversos elementos que lo constituyen. Por otra parte, ambos códices también se asemejan en el modo en cómo construyen su discurso gráfico. Es decir, codifican la información a través de una distribución espacial de sus unidades significativas, lo cual a su vez coincide con los principios generales de la formación del discurso sagrado.

Palabras clave: Códice Borgia; Códice Vindobonensis; discurso gráfico; códices adivinatorios; códices históricos.

\section{[en] Making of the World, Making of the Discourse: Similarities between the Codices Borgia and Vindobonensis}

\begin{abstract}
The aim of this article is to show the existence of some paralel narratives in the central part of the Codex Borgia and in the obverse side of the Codex Vindobonensis. Both codices are eponymous of the so called "Borgia Group" and the "Vindobonensis Group". The first group is formed by "prescriptive codices" and they accomplish with divinatory function. The second set is composed by "descriptive codices" and their content was historic (Jansen 1988, 2002). Nevertheless, this differentiation is not suitable either for the observe side of the Codex Vindobonensis, or for the central part of the Codex Borgia, as both of them register parallel episodes. On the other hand, graphic discourse, understood as a form of encoding information through the spatial distribution of significant units, demonstrates similarities both between these two codices and with the general principles of the construction of sacred discourse.
\end{abstract}

Keywords: Codex Borgia; Codex Vindobonensis; graphic discourse; divinatory codices; historical codices.

Sumario: 1. Introducción. 2. Todo empieza con el viento. 3. Creación de días y noches. 4. El discurso gráfico. 5. Conclusiones. 6. Referencias.

1 Instituto de Estudios Ibéricos e Iberoamericanos, Universidad de Varsovia. k.mikulska@uw.edu.pl. Este artículo es uno de los resultados llevados a cabo dentro del proyecto financiado por los medios del Centro Nacional de Ciencia de Polonia (Narodowe Centrum Nauki) con base en la decisión No. NCN-KR-0011/122/13.

2 Centro de Investigaciones y Estudios Superiores en Antropología Social, Ciudad de México. hermann@ciesas. edu.mx. Este artículo es uno de los resultados del proyecto "Sociedad, gobierno y territorio en los señoríos de la Mixteca: Siglos XVI-XVIII" financiado por el Consejo Nacional de Ciencia y Tecnología de México, Ciencia Básica 2015, clave 259015. 
Cómo citar: Mikulska, Katarzyna y Manuel A. Hermann Lejarazu. 2021. «Creando el mundo, creando el discurso: similitudes entre los códices Borgia y Vindobonensis». Revista Española de Antropología Americana 51: 107-135.

\section{Introducción}

El objetivo de este artículo es mostrar dos narrativas paralelas en la parte central del Códice Borgia y en el lado anverso del Códice Vindobonensis, así como ciertas semejanzas que encontramos en la construcción del discurso gráfico en los dos manuscritos prehispánicos.

Ambos documentos fueron considerados por Seler (1990-2000, III: 208) como los más representativos de dos grupos distintos de manuscritos que se llegaron a diferenciar por el contenido de sus temáticas. Los nombres de los códices Borgia y Vindobonensis pasaron a encabezar a cada uno de estos grupos, por lo que aún, hoy en día, se les conoce como "Grupo Borgia" y "Grupo Vindobonensis". En general, los especialistas consideran al Códice Borgia y al Códice Vindobonensis como manuscritos distintos ya que, de acuerdo con la conocida diferenciación de Maarten Jansen (2002: 285), al "Grupo Borgia" pertenecen los "códices prescriptivos" que tenían la función mántica o adivinatoria; mientras que el "Grupo Vindobonensis" lo conforman los "códices descriptivos" debido a su contenido histórico (Jansen 1988, 2002). Un ejemplo empleado por Jansen para ilustrar esta diferencia es el signo que representa "conquista" (una flecha clavada en un cerro o templo), elemento que para los códices descriptivos señala que ocurrió un conflicto a manera de hecho histórico, mientras que el mismo signo, en los manuscritos adivinatorios, sólo indica la posibilidad de tal suceso, sin que se exprese, unívocamente, si se trata de logros o repercusiones de una conquista.

Empero, el mismo Jansen (1988: 96) señaló que esta división no es categórica, ya que es lógico que el hombre pueda utilizar un libro para otros fines que los propuestos originalmente. Nuestra idea es que justamente esta diferenciación se desvanece en el contenido y en la forma del lado anverso del Códice Vindobonensis y en la parte central del Códice Borgia.

El Códice Vindobonensis en su parte anversa registra un relato en el que se configura el origen de la Mixteca a través de una deidad muy importante en la región: 9 Viento, Coo Sau o Serpiente de Lluvia, quien lleva a cabo una serie de rituales y ceremonias para ordenar el universo mixteco y dar origen, a su vez, a los gobernantes que fundarán los pueblos y señoríos que caracterizan a todo este enorme territorio. La parte central del Códice Borgia -aunque su interpretación está lejos de haberse concluido- consta de una serie de episodios narrativos de acuerdo con lo señalado por diversos investigadores. Entre las interpretaciones más recientes (de las que haremos referencia a lo largo de este artículo -y desafortunadamente por razones de espacio omitimos otras-), citamos las elaboradas por Anders, Jansen y Reyes (1993: 45-48, 175-245) quienes, apoyados en Karl A. Nowotny (2005), interpretan la sección central como una serie de rituales muy complejos que llegaron a conformar un tipo de "protocolo" para los mismos 3 .

Una interpretación a primera vista divergente de la anterior es la de Elizabeth Boone (2007: 171-210), para quien la parte central del Códice Borgia trata de varias

3 En similar dirección va la explicación de Juan José Batalla (2008: 407-441), aunque no sin ciertas diferencias, en las que no profundizamos aquí. 
narrativas míticas, y de similar opinión es Angélica Baena (2014). Pero tal vez entre todas estas interpretaciones hay más semejanzas de lo que parece a simple vista, pues un ritual es también una "reactivación" del mito o historia sagrada (Jansen 2012: 85), por lo cual la pregunta sería más bien de qué manera y en qué momentos se usaba esta parte del códice, y para qué servía.

A día de hoy no es posible afirmar cómo sería el discurso pronunciado por un especialista docto en el uso de los códices históricos mixtecos o bien en los adivinatorios; si es que el discurso gráfico se vertería, se transposicionaría (usando el término de Brokaw 2010: 127) o se transmutaría (usando el término de Mikulska 2015a: 311) al verbal. No obstante, la comparación indirecta con el discurso oral ceremonial o ritual usado en contextos similares permite suponer que en ambos casos se trataría de un discurso rebuscado, formalizado y distinto del "cotidiano" (cf. Mikulska 2008: 63-74, 2010), como "parangón". Este último término se usa con referencia al discurso oral aplicado a la hora de evocar el momento de la creación y a los dioses que intervinieron en el origen del hombre, el culto y los lugares sagrados (López García 2007). Así, es uno de los llamados "lenguajes sagrados" (cf. López Austin 1967: 1-36; Jansen 1985: 3-13; Zumthor 1986: 53; Hermann y Libura 2007; Jansen y Pérez 2008: 88; Mikulska 2008: 63-68, 2015a: 255-266), es decir, un registro particular del lenguaje utilizado para la comunicación con el mundo divino, no-humano o sobrenatural, y que se caracteriza por su carácter formalizado y "formulaico", con presencia de paralelismos, acumulación, redundancia comunicativa y relativa libertad en componer unidades de significados. Tomando en cuenta tanto el contenido del Códice Borgia como del Vindobonensis, pues ambos códices tienen que ver con historias sagradas y el mundo divino, es lógico suponer que el registro gráfico aplicado en ellos difiera del que se aplicaría para tratar temas "mundanos", como sería, por ejemplo, el contenido de la parte tributaria del Códice Mendoza. Uno de los rasgos eminentes presentes tanto en el discurso ceremonial oral, como en el gráfico, es el uso de los llamados difrasismos, multifrasismos (Mikulska 2008: 69-77, 2015a: 357-425), cadenas (Montes de Oca 2013: 82-83) o series difrásticas (Baena 2014), digrafismos cuando se trata de su versión gráfica (Mikulska 2010: 356) o, según la propuesta más reciente de Danièle Dehouve, series metonímicas (2011: 157-158, 2019, entre otros). Según dicha autora: "la unidad semántica del discurso ritual mesoamericano no es la palabra, sino la asociación de varias palabras en 'series', que definen una cosa, un ser o un acto por medio de la enumeración de sus componentes o manifestaciones", haciéndolo por medio de la metonimia (Dehouve 2019: 95). Como tal, pueden ser expresadas en forma verbal, material, teatral y gráfica (cf. Mikulska 2008: 69-77, 2010, 2015a: 255-266; Dehouve 2009, 2014, 2019: 95-96). Es importante notar también que los componentes de la misma serie pueden variar entre estos distintos medios, ya que el uso de cierta palabra o de signo gráfico puede resultar más cómodo o ser el más acostumbrado en uno de estos medios (Mikulska 2010: 330-356). Por lo tanto, nuestro objetivo será analizar el discurso gráfico presente en los episodios descritos, pero sin buscar de manera forzada una correspondencia cien por ciento directa entre éste y el discurso oral, ya que ambos medios ofrecen soluciones distintas para la codificación del mismo contenido.

La noción de las series metonímicas permite escapar de la diferenciación entre los difra- o multifrasismos y las expresiones paralelísticas, estas últimas bien identificadas para distintos discursos orales mesoamericanos (cf. Tedlock 1983: 123; Montes de Oca 2013: 37-38), si bien también se ha usado este último término con referencia a las expresiones gráficas (Jansen y Pérez 2009: 14-15; Craveri y Valencia 2011; Mikulska 2015a: 360-397; entre otros). Los paralelismos son otra figura de la retórica, que consiste en 
repetir parcialmente un fragmento de discurso, lo cual, aparte de contribuir al significado, proporciona pautas estructurales del mismo. Justamente las series metonímicas tienen la tendencia de ir organizadas en grupos paralelísticos (Dehouve 2011: 159-165), pero mientras en el medio oral esto se percibe en la dimensión del tiempo, en el medio gráfico esto se da en la superficie gráfica (Harris 1999: 184-185; Mikulska 2015a: 295-286), en particular haciendo uso de simetrías y oposiciones visuales.

Para poder analizar el discurso gráfico en ambos códices, analizaremos primero el contenido de dos episodios paralelos presentes en la parte central del Códice Borgia y en las primeras páginas del anverso del Códice Vindobonensis. Una comparación de más episodios exigiría de una extensión mucho más grande que la de un artículo, por lo cual nuestro análisis solo se podrá tratar como inicial. Las dos secciones escogidas para este artículo son las que tienen lugar en las páginas 29 y 30 del Códice Borgia; mientras que para el Códice Vindobonensis seleccionamos las páginas 52, 49, 48, 47 y 37, que parecen corresponder con el contenido del manuscrito adivinatorio mencionado.

\section{Todo empieza con el viento...}

En la primera lámina de la parte central del Códice Borgia (Figura 1) la escena está colocada dentro de un marco cuadrangular en forma del monstruo terrestre o una deidad del cielo (cf. Mikulska 2008: 150-155; Díaz 2015: 77-83). En el centro hay un círculo negro, encima del cual está una vasija de color turquesa con una serie de banderas colocadas sobre una forma ovalada: arriba de ésta se encuentra un personaje esquelético negro y varios seres serpentinos de diferentes colores localizados alrededor.

Las interpretaciones anteriores de esta imagen varían notablemente entre sí. Para Anders, Jansen y Reyes (1993: 192-194; cf. Jansen 2002: 302-306), el círculo negro corresponde a un hoyo en la tierra, sobre el que está colocado el brasero "divino que es como un espectro". Lo que está dentro de él es una "poción mágica, la unción alucinante, la comida de los dioses"4, de la cual, gracias al acto de autosacrificio del pene por el personaje negro esquelético -Venus Muerto-, cobra fuerza y causa que "todos los sacerdotes presentes entran en trance". Para Boone (2007: 179), esta imagen representa un estallido de la energía creativa primordial, fuente del poder propio de la suprema fuerza creativa de Tezcatlipoca y de Quetzalcoatl. Una opinión distinta es la de Baena, para quien este elemento, al parecer, "podría hacer alusión al desprendimiento del viento de la noche, el cual aparece como una bola de zacatapayolli, donde se colocarían las ocho banderas de autosacrificio" (2014: 206).

Veamos con más detalle los elementos que componen esta escena para proponer nuestra interpretación. Comencemos por la vasija, en la que se resalta su color turquesa y los motivos antropomórficos y esqueléticos que la integran, como la mandíbula descarnada, los brazos y las piernas huesudas y los ojos dibujados con una gruesa ceja. Este tipo de ojos es propio de seres "no humanos", que no pertenecen al mundo humano y que tienen el poder de ver en el mundo divino o en el de los muertos/ancestros (Mikulska 2017: 49). Como mencionamos, la olla está dotada de miembros esqueléticos (véase la presencia de huesos en lugar de las pantorrillas) que terminan en garras, y además está enriquecida con los órganos interiores del cuerpo

4 Los autores deben pensar en el famoso teotlacualli (“comida divina”) descrito por Diego Durán (1984 I: 51-52), como, por cierto, confirma Jansen en otro texto (2002: 303). 
humano (aunque pintados en forma estilizada) ${ }^{5}$. Dado que así se suele pintar a las deidades huesudas de Mictlan o el Mundo de los Muertos, estos elementos, en nuestra opinión, indican que tanto esta vasija "espiritada"6, como el dios Mictlantecuhtli, operan en el mismo ambiente que calificaríamos "de los muertos" o "de los ancestros". No obstante, en la misma imagen están presentes otros elementos que llevan hacia otro significado, que es la creación. Es decir, la presencia del hueso indica no sólo la muerte, sino también la siguiente recreación (cf. Furst 1982; López Austin 1995: 173-174; Mikulska 2008: 197-274; entre otros), así como la olla también da el valor de lo $\mathrm{creado}^{7}$. Adicionalmente, en la imagen están agregados otros signos que refuerzan el valor semántico de la creación: la olla está pintada con piernas y brazos abiertos a sus lados, que es por excelencia una postura creadora (paridora o fecundadora), propia de la tierra y de deidades responsables de creación de nueva vida como fruto de su cuerpo sexuado (cf. Mikulska 2008: 140-174, 2015a: 80-81).

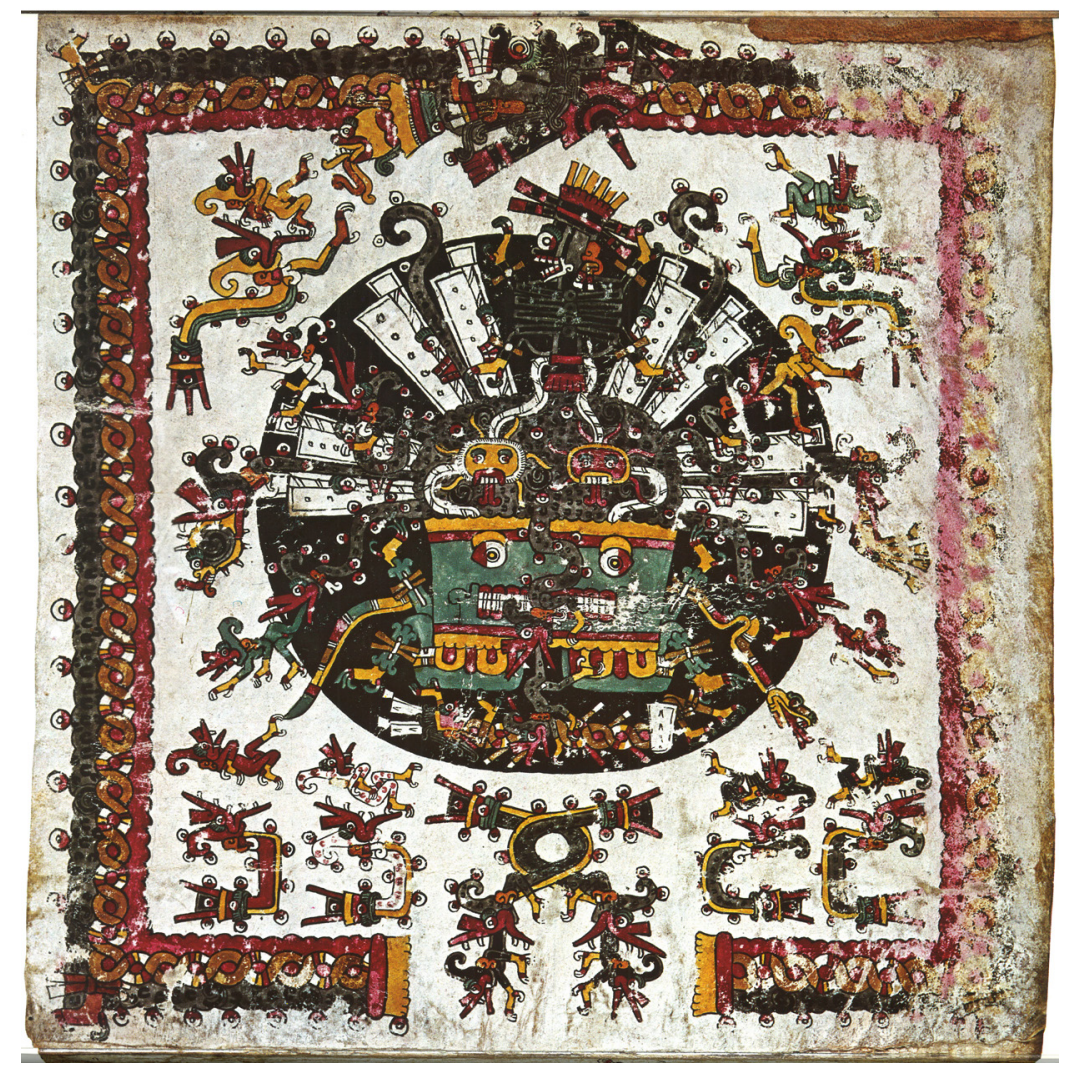

Figura 1. Primera lámina de la parte central del Códice Borgia, lámina 29.

5 Utilizamos esta denominación siguiendo a Gordon Whittaker (comunicación personal, 2013) -a quien asimismo agradecemos-, y quien la usa para el glifo EL (o EL[L]EL), tal como aparece, por ejemplo, en el topónimo Tanpatel (Códice Mendoza f. 10v).

6 Las "vasijas espiritadas" o god pots son, según Jansen (2002: 306-314), las vasijas cuya función consistía en "la comunicación entre el ser humano y los poderes superiores de la naturaleza" y que formaba el "eslabón de comunicación" entre los dioses y los hombres.

Recuérdese el mito de la creación de los humanos de los huesos molidos y echados a la vasija de chalchuihuitl o jade de Cihuacoatl-Quilaztli (Leyenda de los Soles 1992: 146; cf. Mendieta 1993: 78). 
Esta misma postura la ostenta el ser esquelético negro colocado más arriba, por lo cual -en nuestra opinión- el significado al que remite es similar al de la olla, es decir, la muerte y la subsecuente creación. Lo importante es que este ser debe estar realizando el acto de autosacrificio, dado que por debajo de su maxtlatl pasa una cuerda (de la que penden arañas), lo que remite a un acto de sacrificio al que contribuyen también los signos de las banderas blancas, supuestamente de papel (cf. Mikulska 2015a: 445-454).

Sin duda, el elemento que ha causado más discusión entre los especialistas a los que nos hemos referido es la sustancia negra en forma redonda que rellena la vasija. Para poder presentar nuestra interpretación, es necesario introducir la propuesta metodológica de uno de nosotros, de que el sistema de comunicación gráfico empleado en los códices adivinatorios funciona sobre la base de la combinación de tres componentes, que son forma, diseño o patrón, y color (Mikulska 2020a: 347-397). Cada uno de ellos codifica un valor semántico, pero al "llenar" una forma con un diseño distinto, o al plasmar el patrón sobre el fondo de otro color, el significado final puede cambiar, ya que este es el resultado de la confluencia de todos los componentes empleados.

¿Qué es, entonces, este elemento que ha sido identificado como la "poción mágica, la unción alucinante, la comida de los dioses" (Anders, Jansen y Reyes 1993: 192-194), "el estallido de la energía creativa primordial” (Boone 2007: 179) o la bola de zacatapayolli (Baena 2014: 206)?

Como tal, dicho elemento está pintado con el diseño que se asemeja a unas "herraduritas" y espirales negras, colocadas sobre el fondo gris oscuro, todo ello inscrito, efectivamente, en una forma semicircular que se asemeja a una bola de zacate, pero que se va transformando en la forma de serpientes. El mismo diseño se inscribe en otras formas en la misma parte central del Códice Borgia (láms. 30-32, 35-36, 40-42), las cuales, en su mayoría, forman una especie de "recintos" o "fondos" en los que se dan actos de sacrificio o de la creación. Una sola vez en otra parte del códice (Borgia lám. 71) el mismo patrón se inscribe en un rectángulo propio de las formas del cielo, si bien el diseño que está marcando el cielo nocturno suele ser distinto, ya que consta de puntitos y círculos negros. Sin descartar la idea de que ambos patrones, el de las "herraduritas" y el de puntos y círculos, sean variantes que codifican de similar significado, precisamente la forma que podemos describir como "rectángulos con franjas en su parte superior" determina que la composición completa sea la del cielo nocturno, como se puede observar en varias partes del Códice Borgia (láms. 23, 27). La escena superior de la lámina 18 del mismo manuscrito (Figura 2) demuestra de mejor manera esta diferencia: mientras todo el fondo de la escena es oscuro y saturado con el diseño de "herraduritas" y espirales, el cielo nocturno está separado del resto del fondo, estando representado como un rectángulo compuesto de franjas, la más amplia de ellas rellena con el patrón de círculos y puntitos. Dejando el análisis de este último diseño para otra ocasión, lo que podemos decir a estas alturas es que el diseño de "herraduritas" codifica algo oscuro y nocturno, tanto por el contexto de los "recintos" del Códice Borgia anteriormente mencionados, como por representaciones de los topónimos Yoaltepec (“Cerro de la Noche") o Yoallan ("Lugar de la Noche") del Códice Mendoza (ff. 8r, 39r, 40r; cf. Mikulska 2015a: 466-467). Esta idea se confirma adicionalmente con el topónimo de Yayauhquitlalpan o "Lugar del Campo Oscuro/Negruzco" (Códice Mendoza f. 51r; Figura 3a). Dicho lo anterior, podemos concluir que el elemento que sale de la olla de la escena del Códice Borgia analizada codifica a la vez "lo nocturno/oscuro", debido a su diseño, así como el significado cercano a la "bola de zacate" - por su forma semicircular y las banderas de sacrificio insertadas en ella-. Es decir, el significado completo de esta composición implica tanto ser un "objeto de autosacrificio", como su calidad de "nocturno/oscuro". 


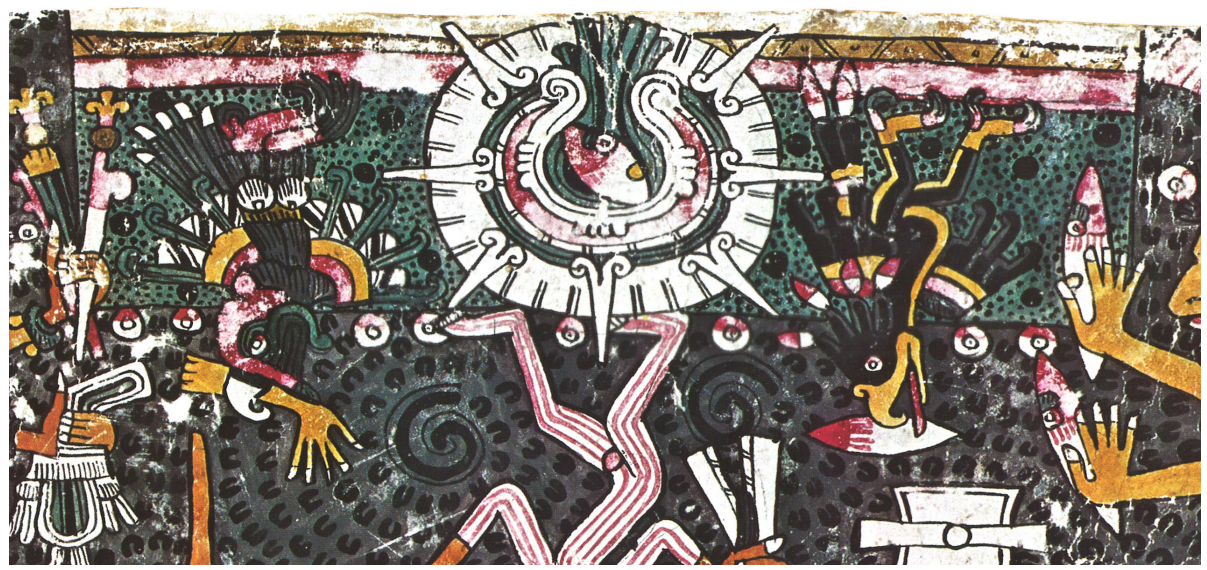

Figura 2. Escena que ocurre en la oscuridad, con marcado cielo nocturno.

Códice Borgia, lámina 18.
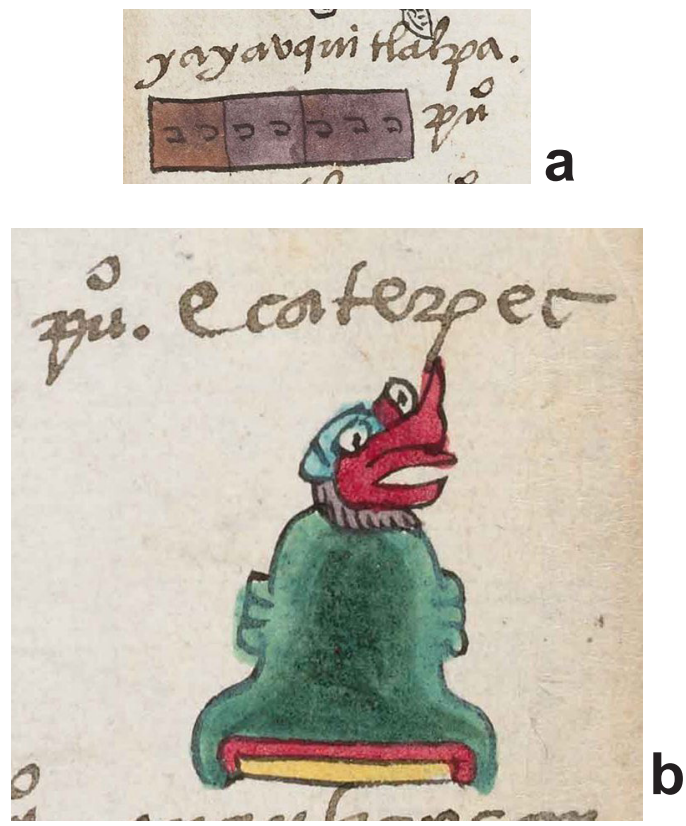

Figura 3. Los topónimos de Yayauhquitlalpan o "Lugar del Campo Oscuro/Negruzco" (a) y Ehecatepec o "Cerro del Viento" (b). Códice Mendoza, folios 51r y 22r (detalles).

A continuación, esta misma sustancia se va convirtiendo o, mejor dicho, el mismo diseño, se va inscribiendo en una forma distinta: en la de siete seres serpentiformes cuyas cabezas terminan en una especie de gancho, mientras que las bocas tienen forma de picos rojos, lo cual es una forma propia del referente "viento", como demuestran varias representaciones del dios del viento, Ehecatl, o bien topónimos tales como Ehecatepec o "Cerro del Viento" (Códice Mendoza f. 22r; 
Figura 3b). Por lo tanto, resulta muy convincente que estos seres representan lo que en náhuatl se ha denominado con el difrasismo in yohualli in ehecatl, "la noche, el viento", como han subrayado Jansen (2002: 302-306) y Boone (2007: 179). Si nos guiamos por la explicación directa de Sahagún, corresponde a "la noche u obscuridad y el que se transfigurã en diuersas formas" (Códice Florentino 1950-1982 [en adelante: $C F$ ] VI: 254).

El siguiente conjunto de elementos bajo análisis son los objetos o seres que emergen de los picos de las serpientes "la noche, el viento". Cinco de ellos, colocados alrededor de la escena central, poseen garras, y sus cabezas rematan en el mismo gancho que los seres serpentinos. Según Boone (2007: 179), son "esencias, personificaciones y agentes anónimos de acción", pero por la presencia de los picos rojos se pueden identificar como vientos. Otros dos elementos, colocados a los dos lados de la escena principal, son una piedra y una planta, par que Boone interpreta como un difrasismo que remite a armas o instrumentos de sacrificio (2007: 180-181). Baena, por su parte, lo considera digrafismo -término adaptado de uno de nosotros (Mikulska 2010: 356)-, aunque precisa que este par forma parte de toda una serie difrástica representada en forma gráfica que se refiere al castigo (Baena 2014: 205-206). Por lo tanto, esta autora identifica la escena completa como "relacionada con el autosacrificio, la expiación (castigo), la purificación y petición de dones" (Baena 2014: 204).

Por nuestra parte, no necesariamente coincidimos con la denominación de este complejo por medio de las palabras como "expiación" o "castigo" -lo cual implicaría cierta "culpa" anterior, que lleva a pensar en los conceptos cristianos-, aunque sí, en entenderlo como autosacrificio y petición de dones. Es decir, quizás habría que comprender toda la serie metonímica del acto de autosacrificio -las banderas sacrificiales, el elemento de la "bola" en la que se insertan instrumentos de autosacrificio ensangrentados, más la piedra y el árbol-como referente a un acto de realizar "lo que se debe" para propiciar una sucesiva creación o recreación. Empero, nos parece aún más convincente la opinión de Baena de que se trata de la aparición de "las entidades conocidas como «aires», causantes de enfermedades y también portadores de lluvia y representantes de las potencias naturales" (Baena 2014: 204). Además, la autora subraya que los aires representados en el Borgia son de cinco colores distintos, y tal percepción del viento y de los aires - de un color distinto en cada rumbo cósmico- persiste hasta hoy en día (Baena 2014: 207). Con base en distintos estudios etnográficos contemporáneos, Baena argumenta que estos aires no solamente son potencias peligrosas del inframundo, sino que también son seres necesarios para la vida y los que traen la lluvia. Nuevamente, no necesariamente estamos de acuerdo con toda la interpretación de nuestra colega -quien considera que la escena completa es una representación de una petición de lluvia, de la abundancia, del cese de la enfermedad, precedida por el acto de expiación (Baena 2014: 207)-, pues no hay ninguna indicación directa al agua o a la lluvia en esta escena del Códice Borgia, a diferencia de lo que ocurre en la página 47 del Códice Vindobonensis (ver infra), en donde el Sr. 9 Viento carga el cielo sobre sus espaldas y distribuye las aguas primordiales en la Mixteca. Pero sí,

8 En este aspecto se trataría de un concepto similar que el identificado por Ulrich Köhler (2001) y expresado por medio de la palabra nahua ixtlahua, "pagar lo que se debe" en el sentido de una obligación moral o bien un acto de intercambio constante de dones entre los dioses y los humanos. 
nos parece indudable, regresando al caso del Borgia, es que se trata del nacimiento de los vientos o los aires, que son los que inician los actos de creación, ya que ésta era la principal función del prehispánico dios del viento (cf. Sahagún 1989 I: 39; Proceso del Santo Oficio contra Mixcoatl y Papalotl... 1912: 54-55; entre otros).

Retornando al Códice Vindobonensis, llama la atención que el personaje principal encargado de realizar diversos actos de creación sea el señor 9 Viento. Su papel protagónico en el relato mixteco se hace notorio desde que se muestra su nacimiento dentro de un cuchillo de pedernal (lám. 49, Figura 4a) y en el momento en que realiza su descenso a la Tierra por medio de una cuerda, después de recibir instrucciones de los dioses ancianos (lám. 48, Figura 4b).
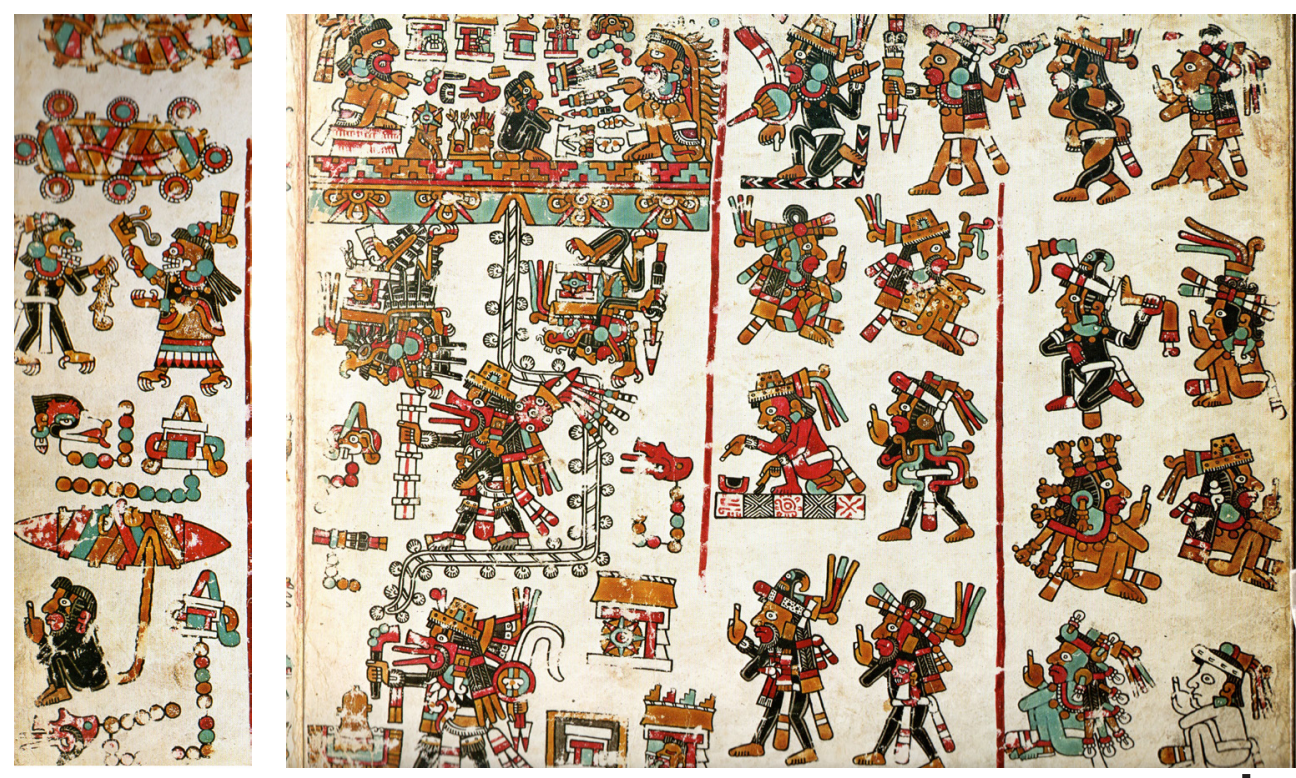

a

Figura 4. Inicio de la historia de 9 Viento. Códice Vindobonensis:

a) lámina 49 (fragmento); b) lámina 48 .

El señor 9 Viento se presenta en la Tierra con los instrumentos y símbolos sagrados del poder que serán colocados dentro de los templos durante la fundación de las dinastías mixtecas. Pero quizá los actos de creación más sobresalientes de 9 Viento se representan cuando carga los cielos con las aguas primordiales y reparte las aguas en toda la Mixteca (lám. 47; Figura 5). Cargar el cielo con las aguas que se derraman o escurren desde lo alto, parece simbolizar el momento de las primeras lluvias que son distribuidas por 9 Viento en diversos lugares de la Mixteca. Pero también esta agua aparece formando ríos, corrientes, mares e incluso, quizá, huracanes. Con el agua esparcida en las montañas de la Mixteca, el espacio sagrado está listo para la aparición de los pueblos, lugares y señoríos más importantes que conforman la geografía y el paisaje sagrado de la Mixteca. 


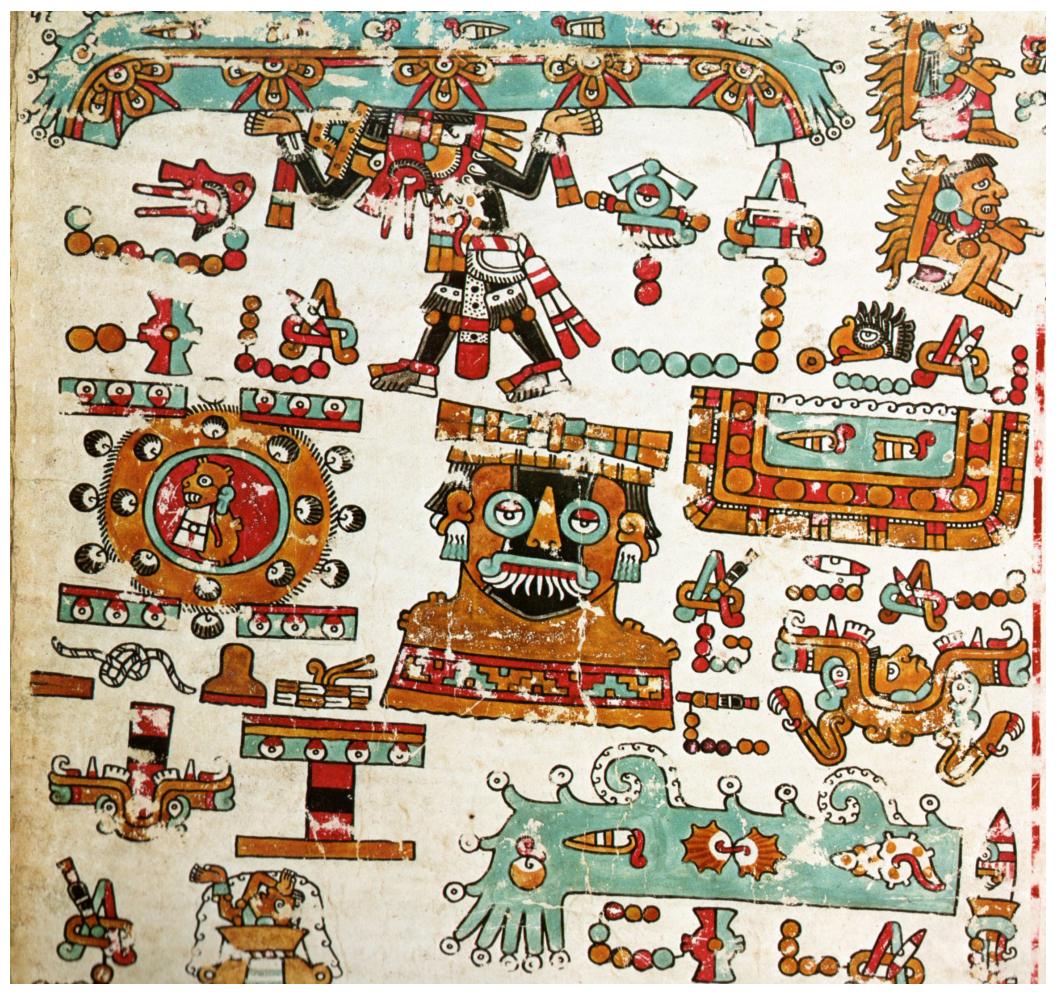

Figura 5. El personaje 9 Viento bajando el agua del cielo. Códice Vindobonensis, lámina 47.

Quizá el siguiente acto de creación más importante en el que interviene 9 Viento sea el propiciar el surgimiento de hombres y mujeres del árbol colocado en el valle de los copales ardientes. Es muy famoso el relato del nacimiento de los primeros hombres en los árboles del río de Apoala (Reyes 1976; Burgoa 1997). Estos árboles, según los textos coloniales, dieron origen a numerosos guerreros que se extendieron por toda la Mixteca para establecer y fundar sus señoríos. Autores modernos como Nowotny (2005), Jansen (1982), Anders, Jansen y Pérez (1992) y Furst (1978), propusieron un vínculo directo entre el "relato de los señores de Apoala" con la imagen del gran árbol del Códice Vindobonensis (lám. 37; Figura 6), por lo que estos autores identifican el Valle de los Copales Ardiendo con el Valle de Apoala.

Aún es necesario realizar nuevas investigaciones para confirmar dicha propuesta, pero fijando nuestra atención a la lámina $37 \mathrm{del}$ Vindobonensis (ver Figura 6), vemos un enorme grupo de personajes surgiendo del centro de un árbol cuyo tronco ha sido partido a la mitad y en cuyas raíces se halla la cabeza de una mujer relacionada, quizá, con la Tierra o con el aspecto femenino del árbol. Al parecer, desde el inicio del tiempo, el árbol ya se encontraba en el Valle de los Copales Ardiendo, pues en la página 50 de este mismo códice se observa un grupo de personajes con características pétreas y vegetales llevando ofrendas de copal y piciete al gran árbol de origen antes de que se efectuara el nacimiento de 9 Viento. 


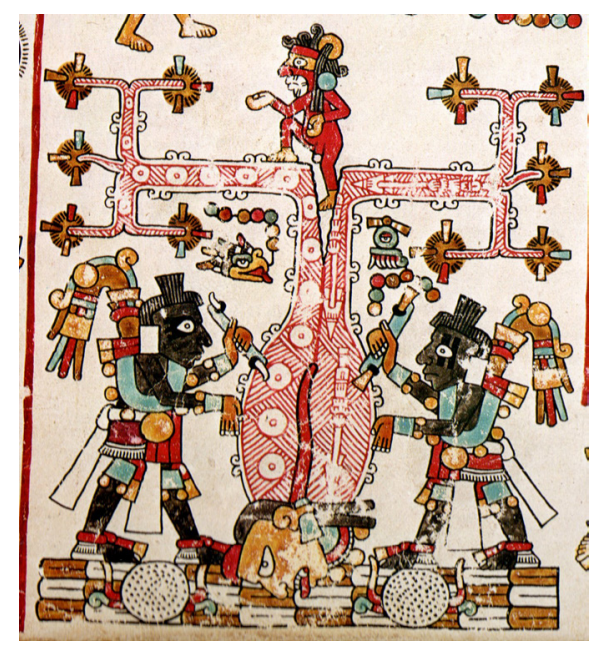

Figura 6. El Gran Árbol en el Valle de los Copales Ardiendo.

Códice Vindobonensis, lámina 37.

\section{Creación de días y noches}

En la siguiente escena de la parte central del Códice Borgia (lám. 30; Figura 7) se aprecia nuevamente un círculo colocado en el centro, y en el contorno de la página se forma un marco con elementos de la diosa terrestre-celeste. Esta vez el círculo es rojo por dentro y negro por fuera. Mientras Anders, Jansen y Reyes (1993: 194) consideran que se trata de una transformación de la rueda negra en un círculo de luz, para Baena (2014: 209-212), quien parte de la interpretación de Seler, es una representación de una joya o chalchihuitl, que al mismo tiempo es extremadamente similar a las imágenes del Sol (Mikulska 2015b: 112; 2017: 45). En realidad, estas interpretaciones no se excluyen, ya que el Sol se representaba precisamente como el glifo de la piedra preciosa (jade o turquesa), enriquecido con los rayos rojos y con una amplia franja amarilla, todo lo cual indica que conceptualmente el Sol se percibía como una "joya que emite luz/calor" (Mikulska 2017: 45, 2020b: 537; cf. descripciones del sol en $C F$ VII: 7).

De las interpretaciones previas también nos parece importante la de Boone, quien indica que dentro del círculo rojo se encuentran las serpientes "noche, viento" (las yohualli ehecatl) y las esencias del viento, que sostienen "recién introducidas bolsas de copal, como si hubieran traído copal como el elemento de sacrificio de la escena anterior" (Boone 2007: 181) .

Alrededor de la rueda del centro se encuentran los veinte signos de los días, acomodados en forma circular. Cuatro de ellos - cipactli $^{10}$, miquiztli (muerte), ozomatli (mono) y cozcacuauhtli (zopilote)- están colocados dentro de círculos. A nuestro parecer, con el fin de acentuarlos, están siendo apuñalados con punzones de hueso.

$9 \quad$... the wind essences hold out newly introduced copal bags, as if they have brought copal as a sacrificial element from the preceding scene (Boone 2007: 181).

10 El nombre del primer signo de los días es el de un animal híbrido y mitológico. Dado que cualquier traducción de este nombre a idiomas indoeuropeos (como sería "lagarto" al español) reduce todo el concepto propio de este signo, optamos por presentar los nombres de los días en náhuatl, uno de los posibles idiomas de los autores del Códice Borgia. 
Esta acción es desempeñada por cuatro seres con el cuerpo negro, cabello amarillo, ojos "no-humanos", colmillos y garras, más con protuberancias en la cabeza. Por lo tanto, coincidimos con Boone (2007: 211) en que este conjunto de elementos representa a seres sobrenaturales o no-humanos, muy parecidos a los ñuhu mixtecos. Estos seres están plasmados sobre cuatro diferentes plantas (de manera similar se suele representar a la diosa Mayahuel sobre un maguey), por lo cual es factible pensar que efectivamente se trata de las representaciones de los espíritus de estas plantas o de ellas mismas antropomorfizadas (Boone 2007: 181). No sabemos por qué serían las esencias de las plantas las que desempeñan la acción de punzar los signos de los días, pero lo que nos interesa es la acción que realizan.

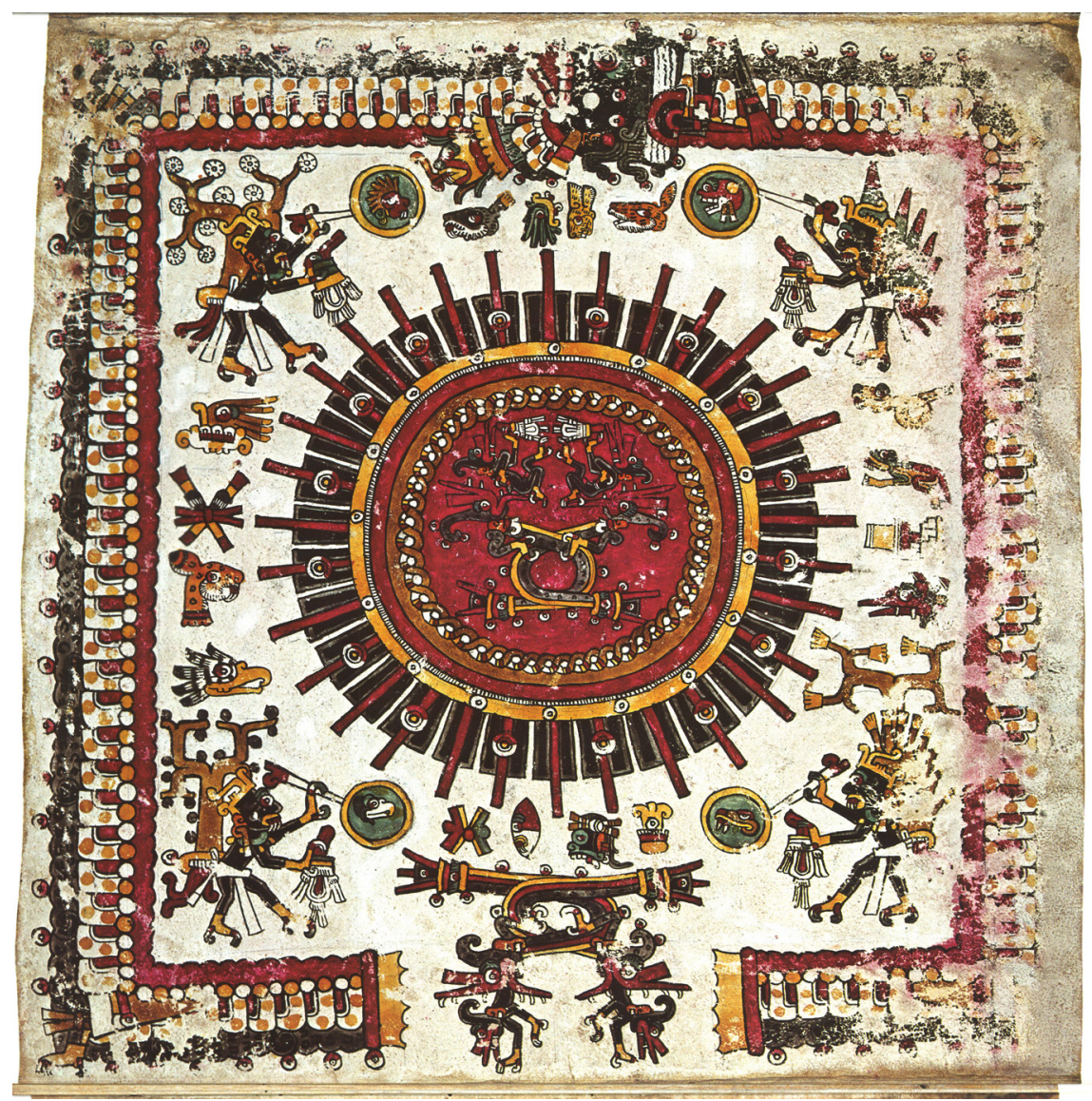

Figura 7. Segunda escena de la parte central del Códice Borgia, lámina 30.

Si bien, el acto de "punzar" está relacionado con el sacrificio, existen también escenas dentro del almanaque de nacimientos en el Códice Borgia en donde los dioses punzan los ojos de los niños indicando que más bien se trata de un acto creativo (cf. Anders, Jansen y Pérez 1994: 251; Boone 2007: 183; Mikulska 2008: 74). Este signo gráfico es al mismo tiempo paralelo al difrasismo in pitza in mamali, literalmente "soplar, taladrar", pero que remite al significado de "nacer, crear" (Boone 2007: 140; Mikulska 2008: 71-74; cf. Montes de Oca 2013: 254). Por lo tanto, estamos de acuerdo con la interpretación de 
Boone (2007: 181-183) de que esta escena representa la creación de la cuenta calendárica de veinte signos, aunque tal vez disponemos de un argumento más que lo confirma.

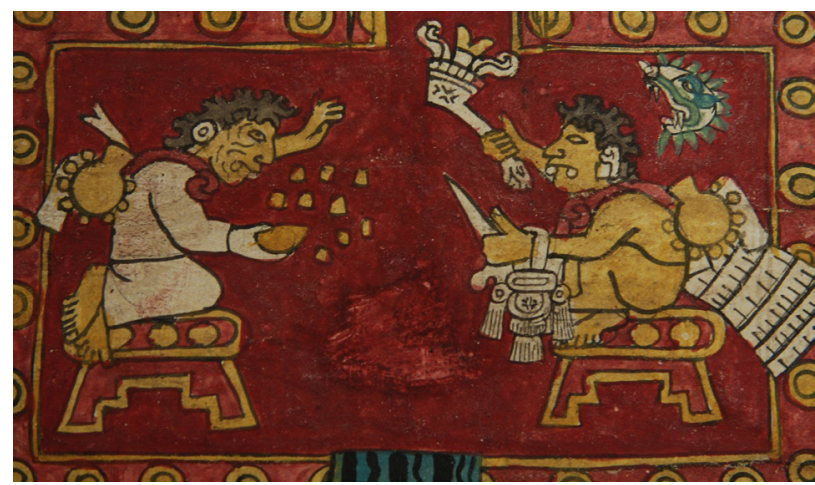

Figura 8. El anciano de la pareja primordial con el punzón de hueso.

Códice Borbónico, lámina 21.

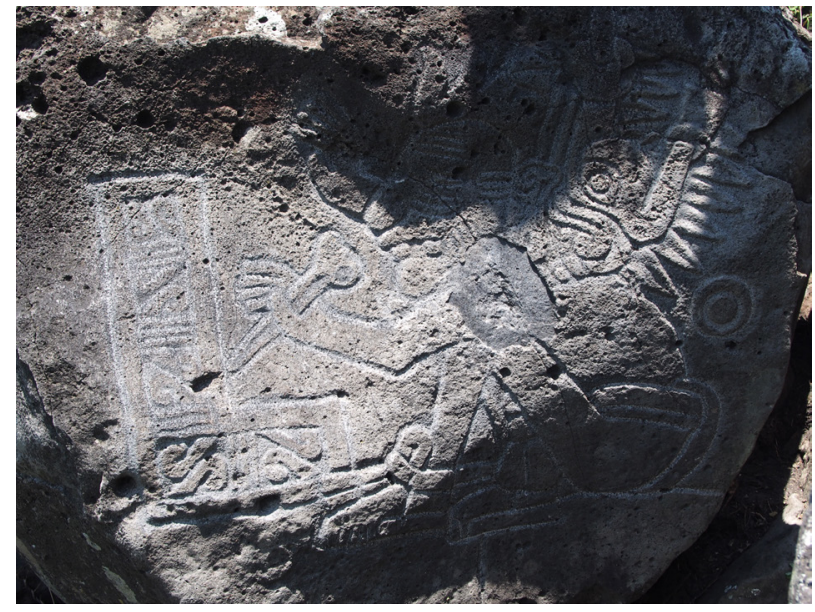

Figura 9. El anciano de la pareja primordial, elaborando el códice con el punzón de hueso. Relieve de Yautepec (fotografía de Katarzyna Mikulska).

El punzón de hueso no es solamente el instrumento para autosacrificio. Conocemos como mínimo dos casos en los que claramente lo lleva también Cipactonal, el anciano que, acompañado de Oxomoco, forman la pareja primordial. Esto ocurre en el Códice Borbónico (lám. 21; Figura 8), cuya pareja está representada en un contexto calendárico. El anciano lleva, además, un incensario tlemaitl o "mano de fuego" (Molina 1980, 2: f. 147r) y una bolsa de copal. Junto con el punzón de hueso, estos objetos, aparte de ser atributos de los sacerdotes ${ }^{11}$, forman una serie metonímica que codifica la ofrenda y el autosacrificio (cf. Montes de Oca 2013: 171-172; Anders, Jansen y Reyes 1991: 181; entre otros). Sin embargo, en los relieves de Yautepec, en

11 Esta es, por cierto, la interpretación de Anders, Jansen y Reyes (1993: 196) de la lámina 30 del Códice Borgia: que se trata aquí de la representación de cuatro sacerdotes de cuatro direcciones. 
los cuales también se representa a la anciana pareja primordial en el acto de creación, Cipactonal aparece con el mismo punzón de hueso - es decir, con sólo un elemento de la serie-, pero lo que está haciendo con él es elaborar un códice (Figura 9; cf. Mikulska 2015a: 38-39, 50-51). Este último es perfectamente reconocible por ser una tira de cinco cuadretes con dos volutas contrapuestas (cf. Mikulska 2015a: 38$39,51-52$ ), que es un reconocido signo de escritura, como se puede confirmar gracias a las famosas imágenes de los tlacuiloque de los códices Telleriano-Remensis (f. 30r) y Mendoza (f. 70r; Figura 10) y las menos conocidas del Códice Xolotl (pl. IV).

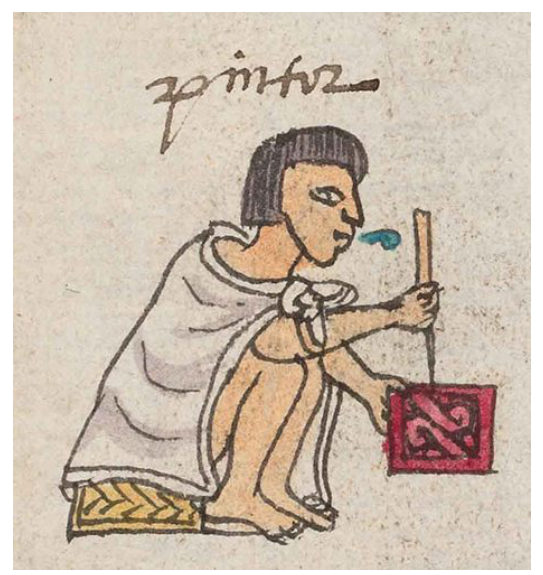

Figura 10. Imagen del tlacuilo. Códice Mendoza, folio 70r (detalle).

La imagen de los dos ancianos de los relieves de Yautepec es la única representación gráfica que muestra a la pareja primordial directamente vinculada con el acto de la elaboración de un códice, aunque su papel en el acto de creación de los libros tonalamatl queda mucho más evidente en los relatos míticos registrados en fuentes alfabéticas nahuas. La más explícita es la historia narrada en el Códice Florentino (X: ff. 140v-142r; [en adelante $C F$ facs.]), según la cual Cipactonal y Oxomoco, acompañados por otros dos ancianos, contestan a la necesidad de poseer "la tinta negra, los colores, los libros, las pinturas" (in tlilli, in tlapalli, in amoxtli, in tlacujlolli) por los humanos, creándoles "la cuenta de los destinos, el libro de los años, la cuenta de los años, el libro de los sueños" (in tonalpoalli, in xioamatl, in xippoalli, in temjc amatl (CF facs. X: f. 142r). En otras versiones de este mito se pone aún más énfasis en la creación de los veinte signos del calendario (cf. Mendieta 1993: 98; Historia de los mexicanos por sus pinturas 2002: 29; cf. Mikulska 2015a: 38-42) ${ }^{12}$. Lo importante es que el origen del calendario es uno de los primeros - y por lo mismo principales- actos de creación realizado por esta pareja - o bien por los cuatro ancianos-. Tomando todo esto en cuenta, incluyendo la imagen del Cipactonal del relieve de Yautepec, el acto de clavar con punzones de hueso los signos del calendario representado en la lámina 30 del Códice Borgia, representa, sin duda, el acto de creación de éstos. Esta interpretación se refuerza aún más por la presencia de las bolsas de copal en las manos de los 12 El relato registrado por Mendieta (1993: 98) difiere de todos los otros en que Oxomoco y Cipactonal están
acompañados por Quetzalcoatl. 
seres-esencias de plantas, ya que estas, junto con los punzones, como hemos visto con el ejemplo del Códice Borbónico, forman una sola serie que implica tanto un acto de (auto) sacrificio anterior, como el subsecuente acto de creación primordial.

Por otra parte, otro de los actos primordiales de creación es echar los granos para hacer la adivinación, como se puede observar en la imagen de la anciana de la pareja del Códice Borbónico (lám. 21; ver Figura 8). Aunque no se puede apreciar de manera igualmente clara, lo más seguro es que en otras representaciones de la pareja primordial, como la de Yauhtepec y la del Templo Calendárico de Tlatelolco, la viejita esté representada de la misma manera, es decir, tiene los brazos extendidos hacia adelante figurando la postura de "arrojar" o "aventar" algo (cf. imagen de la "sortilega" del Códice Tudela, f. 49r) y como asegura Salvador Guilliem (1998: 51). Echar los granos era una de las principales técnicas de adivinación de los antiguos mesoamericanos (Ruiz de Alarcón 1953: 130-131; Serna 1987: 404) y similares prácticas de predicción están presentes hasta hoy en día entre varias comunidades indígenas, como los nahuas de la Huaxteca meridional (Sandstrom 1991: 235-236), los tlapanecos de Guerrero (Dehouve 2014: 200-201) o los mixes del noreste de Oaxaca (Martínez Gracida 2012: 143-166).

Regresando al Códice Vindobonensis, existe un interesante paralelismo en la lámina 52 (Figura 11) -donde comienza realmente el códice-, que nos remite también al origen de los días y, por consiguiente, al origen del calendario mixteco. Una pareja de personajes con el cuerpo pintado de negro está rodeada de diversos elementos. El primero lleva en su entorno 20 ojos o estrellas que, aparte de indicar la calidad de ver en el mundo no-humano, es una clara referencia a la noche, así como también al tiempo-espacio nocturno, onírico y/o de contacto con fuerzas divinas. Mientras tanto, el individuo de la izquierda está acompañado de 20 pequeñas caritas que representan el glifo tacu, nombre mixteco para la semilla o grano de maíz deificado. Por un lado, hay que señalar que, debido al recurso de los tonos, tacu se refiere también a "escritura" (Alvarado 1962: f. 102r), "pintura o pintar" (f. 168r), e incluso "libro" (f. 138r) o, dicho de otro modo, códice, por lo que la semilla deificada se empleaba para leer los códices adivinatorios (Hermann 2008: 143. Figura 11, detalle enmarcado). Por lo que, probablemente, el glifo tacu simboliza el grano de maíz empleado únicamente para fines de adivinación, es decir, es el nombre del grano divinizado en la práctica religiosa de "echar las suertes", y la presencia de los 20 glifos tacu en el Códice Vindobonensis se refiere, quizá, a los 20 signos de los días que conforman el calendario adivinatorio (Hermann 2008: 145).

La conexión del maíz, o más bien de los 20 granos de maíz, con los 20 signos de los días, se confirma también con base en otros documentos nahuas. La ya mencionada pareja de Cipactonal y Oxomoco no solamente es la creadora de la cuenta de los 20 signos de los días, sino también de in tonalpoalli, in xippoalli, "las cuentas de los días, las cuentas de los años" (CF facs. X: ff. 140v-142r; supra), o de yn xiuhtlapohualiztli yn tonallapohualiztli yn çeçempohuallapohualiztli, "la cuenta de los años, la cuenta de los días, y la cuenta de veinte en veinte". En la composición de estos nombres siempre entra el verbo pohua, que se traduce como "contar cosa de cuenta o numero, o relatar proceso e historia, o leer, o dar cuenta el mayordomo de su mayordomia, o cosa semejante" (Molina 1980, 2: f. 82v). Lo que es llamativo es que un derivado de este verbo (en forma aplicativa y con el pronombre tla), tlapohuia, es traducido por Molina como "echar suertes a otro el hechizero", "echar suertes a otro el hechizero o agorero con mayz" y "sortear, echar suertes con cordeles o mayz" (Molina 1980, 2: ff. 120v, 132v, 1: f. 110v). Esto implicaría que los actos adivinatorios de contar los días y echar los granos de maíz eran semejantes a nivel conceptual, lo cual se confirma con otras acciones de la pareja primordial. 
Así, los ancianos Cipactonal y Oxomoco, aparte de crear el calendario, en caso de algún impasse en los actos de creación, son los que realizan un pronóstico y ayudan a los otros dioses a salir de una encrucijada. Así resolvieron el problema de quién debería desgranar el Cerro de Nuestro Sustento, Tonacatepetl, según el relato en la Leyenda de los Soles: "Luego Oxomoco lo contó (quitlapohuia), luego también la mujer de Oxomoco, Çipactonal, contó los días (quitonalpohuia), la mujer Çipactonal. Luego dijeron Oxomoco y Çipactonal, 'solo Nanahuatl golperará a palos el Tonacatepetl', porque lo contaron (oquitlapohuique)" (1992 lado 77: 16-19; trad. KM).

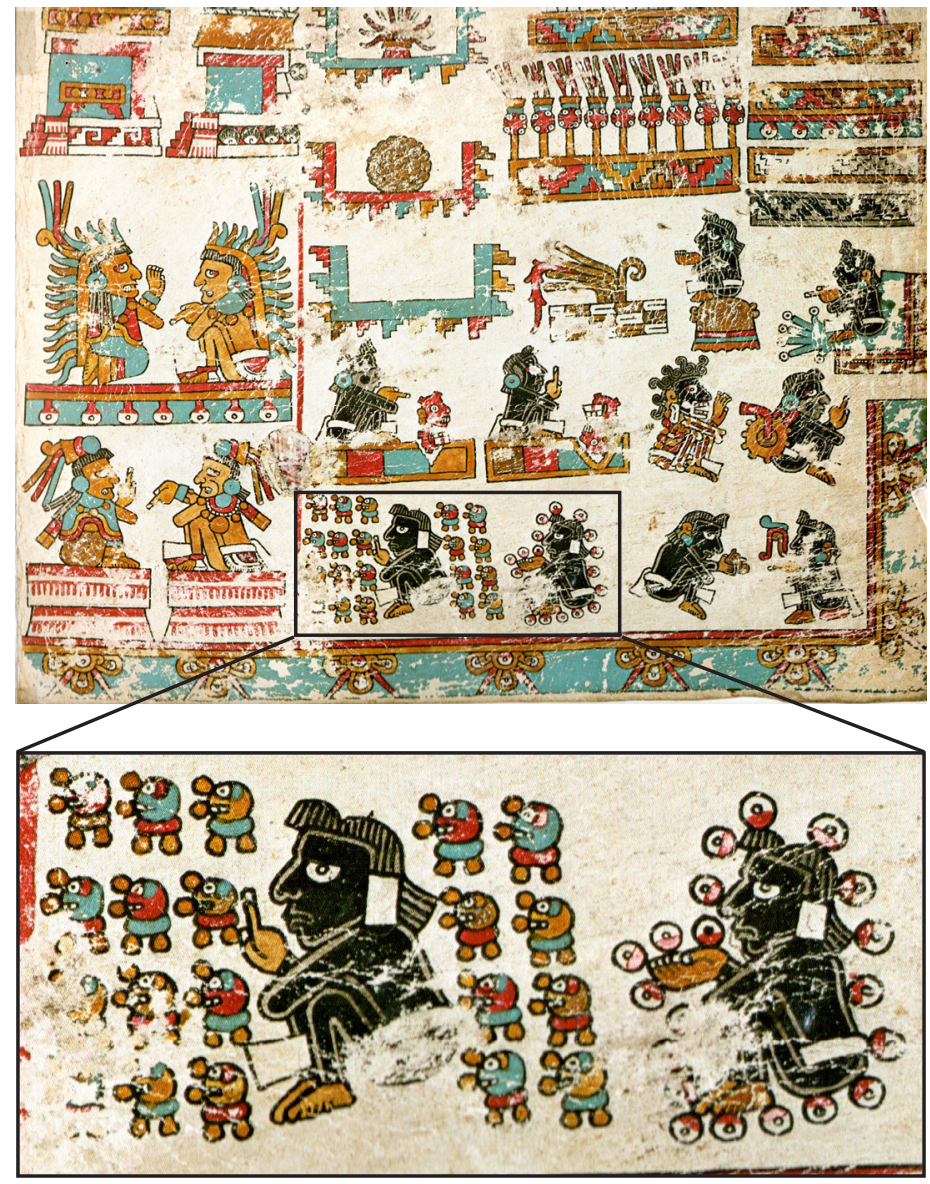

Figura 11. Inicio de la creación en el Códice Vindobonensis, lámina 52, con detalle enmarcado.

Sin lugar a dudas, un acontecimiento similar es el del Popol Vuh de los k'iche', que cuenta cómo los dos ancianos k'iche', Xpiyakok y Xmukane, resolvieron el problema de la creación del hombre:

Entonces, pues, fue la bajada

La adivinación de lo que fue tocado en el maíz en el tz'ite'. 
"!Día

creación!” Les dijeron, pues, una abuela

un abuelo a ellos.

$[\ldots]$

Dijeron, pues, cuando dejaron sembrados los días:

(Popol Vuh 2013: ff. 3v-4r, 19-22) ${ }^{13}$

La pareja k'iche' hace entonces un pronóstico con semillas de maíz y de colorín o tz'ite' (Craveri 2010: 66), pero lo que hacen es "sembrar los días" (supra). Mientras tanto, el acto realizado por los ancianos nahuas, Cipactonal y Oxomoco, se describió utilizando los verbos tlapohuia y tonalpohuia. Ya se ha visto que el primer verbo se utiliza sobre todo para hablar de la acción de echar suertes o echar granos -y contarlos-, mientras que el segundo tiene incorporada la palabra tonalli -se trata entonces de contar los tonalli-. El campo semántico de este último vocablo es muy amplio, ya que se traduce tanto "calor del sol, o tiempo de estio" (Molina 1980, 2: f. 149r, cf. 1: f. 23v), como "dia" (BNF 362, en Gran Diccionario Náhuatl) y "[d]ia natural de veinte y quatro horas" (Cortés y Zedeño 1765, en Gran Diccionario Náhuatl). La cuenta de 260 días se llamaba tonalpohualli, sustantivo derivado del verbo tonalpohua o tonalpohuia, que sería "contar los días-tonalli" (cf. Castillo 2001: 164-165), mientras que los códices adivinatorios eran llamados en náhuatl tonalamatl, literalmente "papel(es) de los días-tonalli" (CF IV: 1, 4, V: 152; Sahagún 1989, I: 44).

Más interesante aún es observar que en las representaciones de los tlacuiloque anteriormente mencionadas, y sobre todo en la imagen de Cipactonal en el relieve de Yautepec, el signo de códice está formado por el signo de dos volutas contrapuestas, inscritas en un cuadrete, por lo cual remiten a "hablar", ilhuia, pero a la vez al ilhuitl o "día" (ver Figura 9) 14 . Este mismo signo puede aparecer colocado en una voluta del habla (Códice Borbónico lám. 4), remitiendo entonces a una comunicación oral, o bien dentro de la tira de cuadretes, refiriendo a los códices tonalamatl, "papel(es) de los días". De esta manera se crea un juego visual y conceptual, consistente en que el mismo signo de "día" y "hablar", inscrito dentro de otra forma, remite a uno u otro medio (cf. Mikulska 2015a: 51-53).

Pasando a las denominaciones correspondientes en mixteco, en el Vocabulario de Alvarado el término "señal", "signo" (1962: f. 188v) ${ }^{15}$ se registra como tnuni, dai, taniño, ndusa. Así también como "adivinar por señales", yo-sini-ndi-tnuni, aunque no queda muy claro cuál de estos términos podría hacer alusión a los "símbolos de los días" o los "días-tonalli". Una posibilidad se encuentra en las diversas acepciones que Alvarado (1962: f. 41v) da para la entrada "calendario", tutu yehendahui quevui, "libro de la cuenta de los días"; porque también registra ñee ñuhuduyu dusa, "piel sagrada de los signos", ñee ñuhu, "piel sagrada" (¿los códices?); dusa, señal, signo, (¿el nombre mixteco para los símbolos de los días?). Por lo que ñee ñuhuduyu dusa, ¿será el nombre mixteco para el tonalpohualli?

13 Siguiendo la forma de apuntar los difrasismos utilizada por Michela Craveri (2013, entre otros) y Mercedes Montes de Oca (2013), ponemos en líneas paralelas los componentes de difrasismos o de series metonímicas.

14 Compárese su lectura como ilhuitl en el Códice Xolotl (pl. X; cf. Mikulska 2015a: fig. 5.e), donde forma parte del antropónimo Cemilhuitzin, "un día" (Thouvenot 2010: 184). Agradecemos esta observación a Gordon Whittaker (2013).

15 Cabe señalar que para la cultura nahua, Sahagún, aparte de denominar los signos de los días como tonalli, emplea también el vocablo machiyotl (CF IV: 1), que según Molina es "señal", "signo por señal", "exemplo o dechado de donde sacamos", "señal. co[m]paracion, exe[m]plo, o dechado" (1980, 1: ff. 108v, 109r, 61v, 2: f. 50v). 
Si bien para la Mixteca no contamos con textos semejantes a la Leyenda de los Soles o el Popol Vuh, al menos encontramos que Alvarado (1962: f. 86r y f. 9v) registra en su Vocabulario las entradas "echar suertes supersticiosas" y "adivinar por suertes", ambas con el mismo término de yo-tasi-ndi noño, donde la raíz o acción verbal es definida por el vocablo -tasi-16. mientras que el vocablo noño, "suerte" (Alvarado 1962: 192v), parece referirse al medio empleado para adivinar el porvenir, en este caso los granos de maíz, pues como lo vimos en el vocablo nahua de Molina "echar suertes", "y echar suertes con cordeles o maíz" emplea el mismo vocablo: tlapohuia. Por lo tanto, si bien Alvarado no registra expresamente las palabras nuni, "maíz", o tacu, "grano deificado", en las entradas referidas, es probable que el término noño, "suertes", sí tenga la misma implicación sobre el uso de los granos para la adivinación, como en el caso de los vocablos nahuas.

Siguiendo con lo representado en la página 52 del Vindobonensis, en la parte izquierda de la lámina, se muestra a dos parejas de ancianos colocados sobre el cielo y en actitud de conversación (ver Figura 11). Ambas parejas no tienen nombres calendáricos ni tampoco glifos que los identifiquen. Es probable que esto sea una indicación para resaltar que los dioses creadores actuaron en una época tan antigua que aún no existía el tiempo ni el calendario, ni había signos para nombrarlos. Vale la pena notar también que, aunque en el Centro de México la pareja primordial se llama Oxomoco y Cipactonal, las fuentes alfabéticas con frecuencia intercambian sus nombres (cf. Anales de Cuauhtitlan 1992 lado I: 25-29; Leyenda de los Soles 1992 lado 77: 16-19; cf. Mikulska 2015a: 68), como si no tuviera mayor importancia cómo se llama él y cómo se llama ella ${ }^{17}$. Por otro lado, aunque no podemos precisar de forma concluyente que alguna de estas parejas mixtecas pudiera equipararse con Oxomoco o Cipactonal del mundo nahua (ni con la pareja k'iche' del Popol Vuh), llama la atención que durante su presencia se haya creado el calendario adivinatorio o los 20 glifos tacu y los 20 "ojos-estrellas" de la noche.

En suma, nuestra idea es que, mientras en el Códice Borgia en la lámina 30 se representa una escena completa de la creación de la cuenta de los días -o de los veinte signos que lo van a constituir-, en el Códice Vindobonensis también hay una alusión muy notoria al origen del calendario, o mejor dicho, al origen de la práctica adivinatoria a través de los granos de maíz deificados que representan los días (glifo tacu) y los "ojos-estrellas", signos que codificaban la calidad de ver en el mundo de fuerzas divinas.

\section{El discurso gráfico}

El último tema a tratar en este artículo, aunque sea sólo a manera de esbozo, es el del discurso gráfico, entendido como una forma de codificación de información por medio de la distribución espacial de las unidades significativas (Mikulska 2015a: 405-424). Como dijimos en la Introducción, la unidad semántica del discurso gráfico (Mikulska 2015a: 357-405), y en general del discurso mesoamericano (en cualquier medio verbal, gráfico, material o teatral), es la serie metonímica (Dehouve 2019:

\footnotetext{
Alvarado registra la entrada "conjurar demonios" con los vocablos yo-tasi-ndisi, yo-cachi-tnuni-ndi. Aunque en representaciones gráficas indígenas (el relieve de Yautepec; Códice Borbónico lám. 21; Códice Borgia lám. 35) el anciano aparece con el yelmo de cipactli, que le asignaría el nombre de Cipactonal.
} 
95-96), y que corresponde a los conjuntos anteriormente llamados difrasismos, multifrasismos, digrafismos, etc. A su vez, las series metonímicas suelen ir acomodadas en grupos paralelísticos (Dehouve 2011: 159-165), y en el medio gráfico lo harán por medio de distintos tipos de simetrías.

Unos de los paralelismos más evidentes, y ya observados hace años en el Códice Vindobonensis por Maarten Jansen (1982, I: 139, 143) y luego por John Monaghan (1990: 137-138), son la serie de personajes colocados después del nacimiento de 9 Viento (lám. 48; ver Figura 4), los cuales son a la vez títulos o, en otras palabras, son la serie que describe/define a esta deidad. Éstos forman pares de manera comparable con los dísticos de la expresión oral, que se podrían describir como "el guerrero con atlatl y flechas, el guerrero con lanza", "el de piel de piedra, el de piel de piedras preciosas ${ }^{18 "}$ y "el que habla, el que escribe" (ver Figura 3, sección resaltada) ${ }^{19}$.

De igual manera, toda la lámina 52, la inicial del Códice Vindobonensis, y en la que comienza la historia, está organizada en "pares semánticos" (ver Figura 11). El primero de ellos son dos figuras negras con dos "elementos" propios para la comunicación con el mundo divino, es decir, el habla (representada por medio de la vírgula) y el tabaco. El siguiente par, que ya hemos visto, son los personajes cubiertos de signos de ojos-estrellas y de los signos de tacu-día-maíz (supra). A continuación tenemos un par de personajes sentados, cada uno frente a un $\tilde{n} u h u$, uno que sale de la hendidura de la tierra y otro colocado en posición opuesta. Luego sigue un par de personajes -aunque no del todo- con características contrarias: uno es esquelético y de cabello enmarañado, y el otro lleva una bolsa de tabaco. Más adelante esta oposición o complementariedad es muy convincente: el río se opone o complementa al cerro; el "Lugar Negro" o Tilantongo (tablero de grecas escalonadas en color negro: Ñuu Tnoo) tiene su equivalente a "Lugar Blanco" o Ñuu Cuisi (¿quizá Zaachila, en los valles centrales de Oaxaca?). Enseguida vemos el "Lugar del Cielo", Nuu Ndehui o Saha andevui, "Al pie del Cielo", una probable referencia a la Mixteca de la Costa (Reyes 1976: II), y quizá, también, a la Mixteca Baja, Ñuu Niñe, pues tal vez se represente por el tablero de grecas Ñu y el asiento del gobernante que, en vez de interpretarlo directamente como tayu, proponemos leerlo como niñe, término relacionado con "reynado", satoniñe, y con "señor grande" o gran señor, yya toniñe (Alvarado 1962: ff. 180v y 188v). Ya en trabajos previos (Hermann 2005 I: 208-210; Mikulska 2008: 70-73) habíamos establecido la relación metonímica entre silla o asiento con el señor o gobernante, pues el asiento le pertenece o es inmanente a su cargo, por lo que se trata de una figura metonímica que se establece a partir de una relación de contigüidad. De tal manera que observamos en la enumeración de los topónimos una clara referencia a la división territorial de la Mixteca.

Finalmente, otros paralelismos pueden encontrarse en la esquina superior derecha de la lámina 52 (ver Figura 11), donde vemos una edificación con el techo adornado con bolas de plumones, así como también en los taludes de la parte posterior y en el tablero del basamento. La siguiente construcción tiene en el interior otro asiento o silla de gobernante, así como grecas en los tableros del basamento. Todos estos elementos, sin duda, refieren a dos espacios fundamentales: el templo, yuqh (identifica-

18 La piel de este personaje está marcada con círculos de distintos colores, de la misma manera como los asientos de autoridad se marcan con piedras de jade, turquesa u oro en los códices Borgia (láms. 9-13, 61-70; passim) y Vaticano B (láms. 52-53, 59-68, passim).

19 Cabe señalar que en la descripción de estos personajes diferimos parcialmente de su identificación hecha por Monaghan (1990: 138). 
do por las borlas de plumones relacionadas al sacrificio), y la casa del señor o la casa del gobernante, el aniñe; lugares ambos muy importantes vinculados a la ceremonia, al culto a los dioses y al gobierno, al poder.

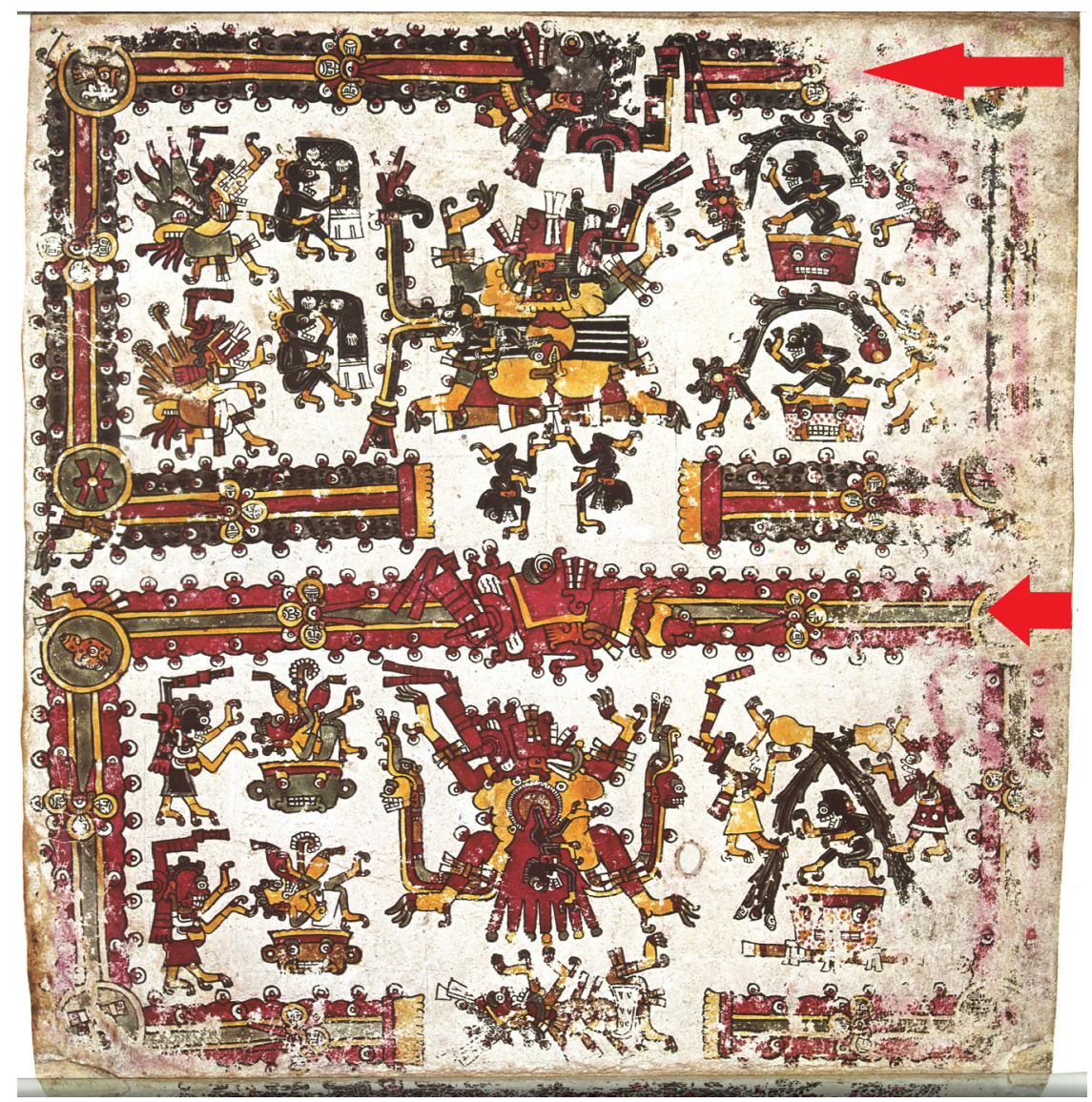

Figura 12. Los marcos en forma del cuerpo de una deidad terrestre-celeste que constituyen la estructura gráfica paralela. Códice Borgia, lámina 31.

Pasando al Códice Borgia, prácticamente toda la parte central del manuscrito (láms. 29-46) está organizada bajo el principio de unidades paralelas (cf. Mikulska 2015a: 417-419; 2019: 64-67). Éstas operan tanto a nivel de estructura de grandes unidades compositivas, como a nivel de una imagen singular. Así, el ejemplo del paralelismo estructural a nivel "macro", es decir, que organizaba o conectaba semánticamente láminas enteras, sería el marco en forma del cuerpo de una deidad terrestre-celeste que rodea las escenas de las primeras dos láminas de esta parte (29-30; ver Figuras 1 y 7; cf. Mikulska 2019: 65-66). Por un lado, en ambas láminas este marco es idéntico (está formado por el diseño de la noche y del ¿día?): tiene brazos y piernas abiertas hacia las cuatro esquinas, la cabeza y el pecho colocados arriba de la escena, y una apertura abajo. Por otro lado, tiene importantes variaciones, ya que la deidad-marco de la lámina 29 es masculina y la de la 30 es femenina, lo cual se nota por la presencia de la falda apenas visible sobre las piernas de esta segunda y, además, por la banda de algodón sobre 
la cabeza (rasgo propio de deidades femeninas; Boone 2007: 175; Mikulska 2008: 98104). Otro elemento cambiante de forma paralela es el "interior" de estos dos cuerpos, formado por una cuerda en el primero y un costillar en el segundo ${ }^{20}$. Las alternancias de cuerpos-marcos siguen en la lámina siguiente, la 31 (Figura 12), que no hemos analizado con detalle en este artículo, pero que vale la pena mencionar brevemente. En ella, las deidades-marco tienen las cabezas -otra vez una con banda de algodón y la otra sin ésta (posible indicador de sexo diferente) - dirigidas hacia lados opuestos, así como sus cuerpos (lo cual se nota en la colocación de los signos de Venus plasmados sobre ellos); éstos están pintados colocando los colores rojo y negro al revés, tal vez indicando la alternancia entre la noche y el día, como sugiere Díaz (2015: 83-85).

Regresando a la lámina 29 del Borgia (ver Figura 1), también se puede observar en ella los paralelismos visuales presentes dentro de la misma escena, por lo cual éstos constituirían el ejemplo de paralelismos a otro nivel que los anteriores. Uno de ellos es parcialmente similar a los ejemplos anteriormente descritos del Códice Vindobonensis: a los dos lados de la escena (en su parte inferior) aparecen pares de serpientes, de cuyas bocas emergen personajes-vientos. Lo relevante es que todos estos seres están organizados visualmente de tal manera que forman pares complementarios tanto con su figura vecina más cercana, igualmente, el par de un lado de la lámina contrasta semánticamente con el del otro lado (Figura 13). Así, el par del lado derecho está formado por dos serpientes, que anteriormente calificamos como "noche/oscuridad, viento", mientras que el del lado izquierdo podríamos calificarlo como opuesto. Esto porque una de estas serpientes es roja -recordemos que el cuerpo de la deidad-marco en ésta y la siguiente lámina se compone de la combinación de parte roja y parte "oscura" (marcada con diseño de "herraduritas")-, mientras que la otra es blanca, con el mismo diseño de "herraduritas", pero ahora rojas. Parece que ambas serpientes del lado izquierdo, de alguna manera, remiten semánticamente a algo "diurno", opuesto a lo "nocturno/oscuro" que es la calidad del par del lado derecho. Al mismo tiempo, ambos pares están colocados de tal manera que, aunque no se encuentran en una proximidad inmediata, la simetría bilateral entre ambos lados de la escena permite conectarlos sin mayor problema. Ésta sería también la diferencia con los paralelismos visuales anteriormente descritos del Códice Vindobonensis, los cuales están colocados como si siguieran una línea narrativa.

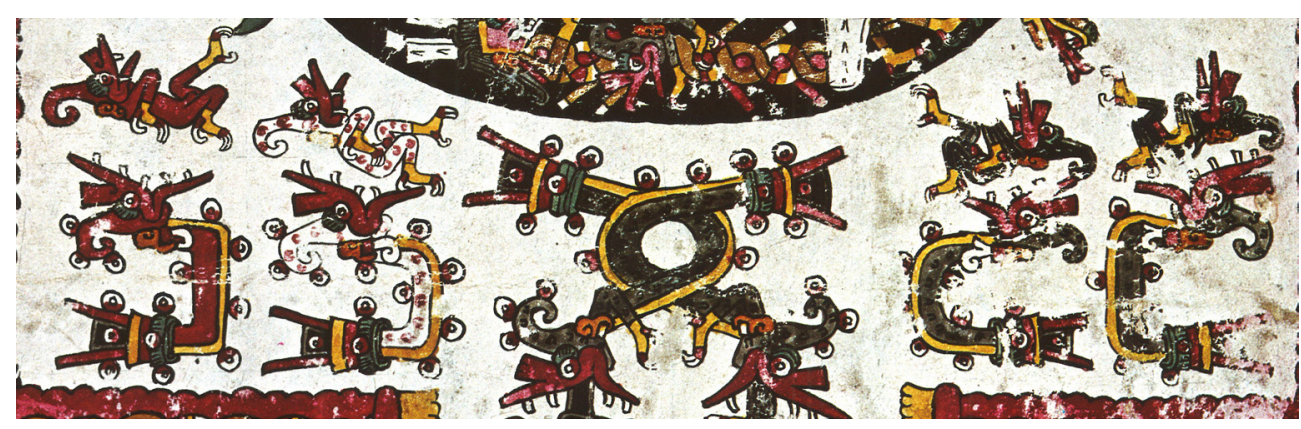

Figura 13. Pares de cuerpos de serpientes formando paralelismos visuales. Códice Borgia, lámina 29, detalle.

20 También dentro de ambos marcos la escena principal está plasmada sobre un cuerpo redondo (cf. Anders, Jansen y Reyes 1993: 192-196; Boone 2007: 179-183). 
Otro tipo de paralelismo visual en la lámina 29 del Borgia se podría calificar como organizado bajo el principio de simetría rotacional. Éste consiste en que elementos paralelos -en este caso cada uno de los vientos que emergen de las bocas de las serpientes "la noche, el viento"- son cada uno de un color, y además van organizados visualmente en forma radial (Leroi-Gourhan 1971: 192-193; Mikulska 2015a: 276-278). Tal organización está muy presente en varios diagramas en los códices adivinatorios (códices Borgia láms. 27-28, 72; Vaticano $B$ láms. 69, 73; Fejérváry-Mayer lám. 1, Ms. Aubin No. 20; etc.; cf. Mikulska 2015a: 278-281), pero también en imágenes particulares, sobre todo las que remiten a un significado relacionado con nacimiento o creación. Entre ellas, de la parte central del Códice Borgia, podemos mencionar a cuatro seres de distintos colores -rojo, azul, amarillo y blanco- que surgen de una bola negra como resultado del baile de un personaje con armas (lám. 33; Figura 14a) o bien el nacimiento de los cinco dioses macuiltonaleque -verde, amarillo, negro, azul y rojo-, junto con cuatro distintos animales, del cuerpo de un personaje sacrificado (lám. 42; Figura 14b. cf. Mikulska 2019: 67-68, 70-71).

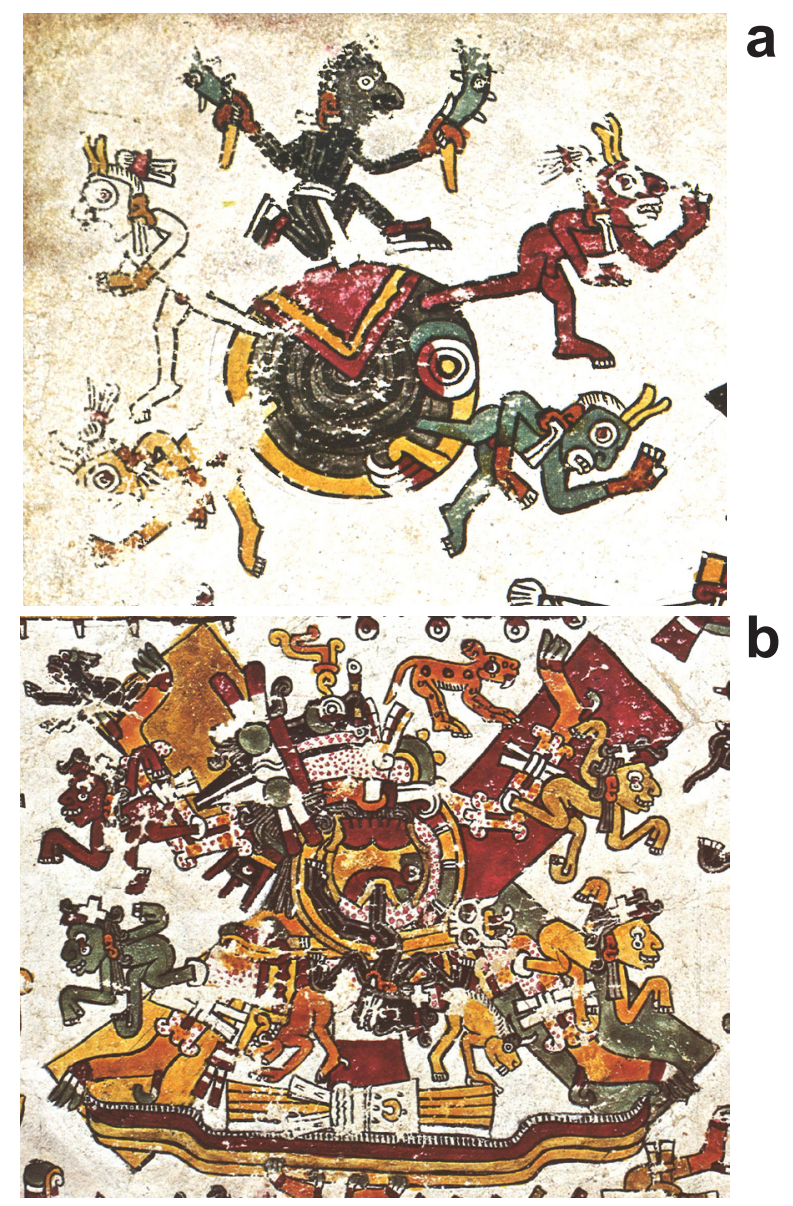

Figura 14. Ejemplos de simetría rotacional. Códice Borgia: a) lámina 33; b) lámina 42. 
Una comparación con fragmentos conservados del discurso ceremonial nahua permite ver que en el medio oral se aplicaban similares paralelismos, es decir, compuestos de cuatro o cinco componentes, que se diferenciaban por los epítetos cambiantes. Así, en el relato de creación del maíz, registrado en forma alfabética en la Leyenda de los Soles, se llama a las deidades tlalloque que van a ayudar a desgranar el monte del sustento, diciendo:

Auh nima ye netlalhuilo in tlaloque:

in xoxouhqui tlaloque

iztac tlaloque

coçauhqui tlaloque

tlatlauhqui tlaloque

(Leyenda de los Soles 1992: 9)

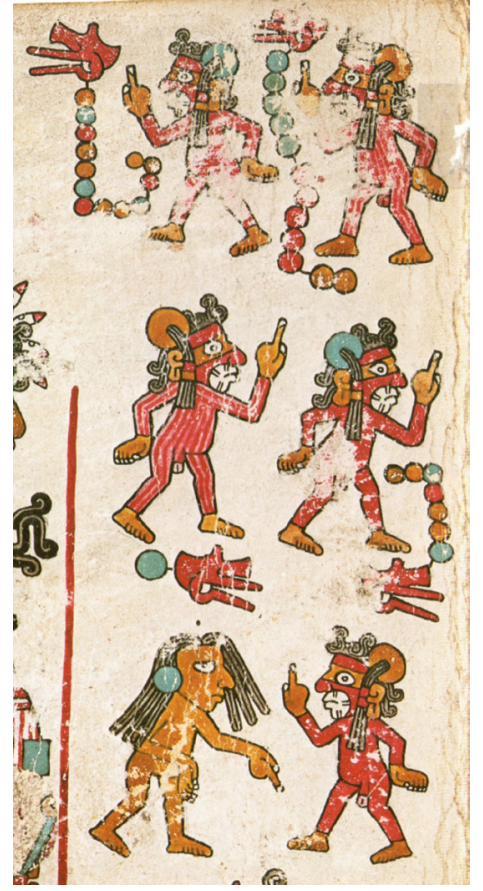

Luego se llamó a los tlalloque:

a los tlalloque verdes, a los tlalloque blancos, a los tlalloque amarillos, a los tlalloque rojos.

Figura 15. La mujer y cinco personajes "macuiltonalescos" paralelos a nivel visual, representados en forma de pares.

Códice Vindobonensis, lámina 51.

En este caso, la serie metonímica que define a todos los dioses tlalloque, enumerando todas sus variantes en distintos colores, está organizada en forma de paralelismo, cuya primera parte se mantiene sin cambios, alternando el epíteto en la segunda parte. De manera similar, en el discurso gráfico se dan casos de nombrar a todos los seres que definen una totalidad por la enumeración de cuatro o cinco colores, pero su agrupación sobre la superficie gráfica va a darse en forma de círculo que, de por sí, da la noción de algo completo. Éste es justamente el caso de los vientos de la lámina 29 del Códice Borgia, que componen una serie paralelística, pero cuyos componentes se pueden agrupar en forma radial. De igual manera, en la siguiente lámina del Borgia (ver Figura 7), los cuatro seres no-humanos o esencias de las cuatro plantas, aunque no se representan emergiendo de un mismo elemento central, guardan un obvio paralelis- 
mo visual -todos son negros, tienen la misma postura y realizan la misma acción de punzar- y el único detalle que difiere en cada caso es la planta misma (como el color en los ejemplos descritos anteriormente). En este caso están colocados en la escena de esta lámina guardando una simetría rotacional, la cual sería imposible de reproducir en el medio oral, reduciéndose en él a la organización paralelística lineal. En este aspecto, el Códice Borgia aprovecha de mejor manera las posibilidades ofrecidas por el medio gráfico, es decir, una organización gráfica significante, basada en las simetrías de distintos tipos. En el Códice Vindobonensis, un fragmento significativo que podría haberse representado de manera similar es el de la lámina 51 (Figura 15): una mujer desnuda y cinco personajes representados como aquél que nace del árbol del Valle de los Copales Ardiendo. El primero de estos personajes "macuiltonalescos" aparece sin nombre, pero los siguientes se llaman 1 Viento, 7 Viento, 12 Viento y 13 Viento. Aparte de la similitud visual de estos últimos, que se diferencian básicamente sólo por el color de su adorno en la cabeza, justamente sus nombres calendáricos también son paralelos, ya que mantienen la parte "viento", modificando solamente el número.

\section{Conclusiones}

El objetivo de este trabajo ha sido mostrar, aunque de forma breve y en cierta manera inicial, que las narraciones de la parte central del Códice Borgia y del anverso del Códice Vindobonensis presentan muchas semejanzas en cuanto a los hechos narrados, a pesar de que en principio pertenecerían a categorías distintas de la clasificación de Jansen -prescriptivo el primero y descriptivo el segundo-. Lo más probable es que la parte central del Borgia y el anverso del Vindobonensis narren acontecimientos míticos de la historia sagrada. En ambos documentos, el inicio de la historia depende de la presencia del viento o de los vientos; en ambos, muy al principio, se narra la creación del tiempo, gracias a la creación de los 20 signos de los días, que a la vez son la unidad del calendario de 260 días, base de todo el sistema adivinatorio. Además, en ambos códices el acto de creación se realiza por un acto previo de ofrendas y autosacrificio.

Gran parte de esta información se registró en ambos códices por medio del particular discurso gráfico, que entendemos como una forma de codificación de información por medio de la distribución espacial de las unidades significativas. Entre estas últimas, en cualquiera de los modos de comunicación mesoamericanos, está la serie metonímica (Dehouve 2011, 2019), aunque no tiene que darse una correspondencia directa entre sus partes constituyentes en distintos medios. Así, el medio gráfico, es decir, los códices, aprovechan la bidimensional superficie gráfica para la distribución de estos componentes, colocándolos en forma paralela. En el Códice Vindobonensis las series son bastante largas, y se organizan en forma de subsecuentes pares de imágenes o componentes que se corresponden entre sí, tanto visual como semánticamente. Mientras tanto, las series en el Borgia hacen uso de simetrías, tanto bilaterales -que consisten en colocar los componentes de la serie en dos lados distintos de la escena, pero en puntos simétricos-, como rotacionales, en las que los componentes gráficos de la serie se sitúan alrededor de un punto central. Esta última configuración quizás se use con la finalidad de dar noción de una totalidad, es decir, enumerar "todos" los elementos que conforman una idea, como todos los (variantes de) vientos, todos los dioses macuiltonaleque o tlalloque, etc. Y finalmente, también en el Códice Borgia observamos la presencia de 
paralelismos que juntaban semánticamente entre sí láminas distintas, creando a la vez un conjunto de ellas, contrastando dos variantes del mismo signo gráfico. Esto no quiere decir que similares o, aún más, distintas soluciones en el discurso gráfico no se observen también en el Códice Vindobonensis; por el contrario, creemos que el estudio de tales modelos apenas queda iniciado.

Finalmente, si bien desde los tiempos de Edward Seler se sabe que la parte central del Borgia contiene narrativas, lo cual implica que no tiene la función adivinatoria propiamente dicha, así como se sabe que el lado anverso del Vindobonensis no registra hechos históricos propiamente dichos, la similitud tanto entre el contenido, como en el discurso gráfico en ambos manuscritos, sugiere que incluso se podrían considerar las narrativas míticas como un género literario particular.

Agradecimientos: Queremos expresar nuestro agradecimiento a Juan José Batalla Rosado, así como al lector anónimo, por las sugerencias y comentarios que han contribuido a mejorar este texto.

\section{Referencias}

Alvarado, fray Francisco de. 1962 (1593). Vocabulario en lengua mixteca, reproducción facsimilar con un estudio de Wigberto Jiménez Moreno. México: Instituto Nacional Indigenista, Instituto Nacional de Antropología e Historia.

Anales de Cuauhtitlan. 1992. En Codex Chimalpopoca. The Text in Nahuatl with a Glossary and Grammatical Notes, John Bierhorst, ed., pp. 1-84. Tucson: The University of Arizona Press.

Anders, Ferdinand, Maarten E.R.G.N. Jansen y Luis Reyes García. 1991. El libro del ciuacoatl. Homenaje para el año del Fuego Nuevo. Libro explicativo del llamado Códice Borbónico. Graz, México: Akademische Druck- und Verlagsanstalt, Sociedad Estatal Quinto Centenario, Fondo de Cultura Económica.

- 1993. Los Templos del Cielo y de la Oscuridad. Libro explicativo del llamado Códice Borgia. Graz, México: Akademische Druck- und Verlagsanstalt, Sociedad Estatal Quinto Centenario, Fondo de Cultura Económica.

Anders, Ferdinand, Maarten E.R.G.N. Jansen y Aurora Pérez Jiménez. 1992. Origen e Historia de los Reyes Mixtecos. Libro explicativo del llamado Códice Vindobonensis. Graz, México: Akademische Druck- und Verlagsanstalt, Sociedad Estatal Quinto Centenario, Fondo de Cultura Económica.

-. 1994. El Libro de Tezcatlipoca, Señor del Tiempo. Libro explicativo del llamado Códice Fejérváry-Mayer. Graz, México: Akademische Druck- und Verlagsanstalt, Fondo de Cultura Económica.

Baena, Angélica. 2014. «Metáforas, metonimias y digrafismos en la parte central del Códice Borgia (29-32)». Itinerarios 20: 199-224.

Batalla Rosado, Juan José. 2008. Codex Borgia. Una guía para un viaje alucinante por el inframundo. Torrejón de Ardoz: Biblioteca Apostólica Vaticana, Testimonio Editorial.

Boone, Elizabeth Hill. 2007. Cycles of Time and Meaning in the Mexican Books of Fate. Austin: University of Texas Press.

Brokaw, Galen. 2010. «Indigenous American Polygraphy and the Dialogic Model of Media». Ethnohistory 57 (1): 117-133. https://doi.org/10.1215/00141801-2009-056. 
Burgoa, fray Francisco de. 1997. Geográfica Descripción de la parte septentrional del Polo Ártico de la América, 2 vols. Edición facsimilar de la obra publicada en 1674. México: Gobierno del Estado de Oaxaca, Universidad Nacional Autónoma de México, Consejo Nacional para la Cultura y las Artes, Universidad Autónoma Benito Juárez de Oaxaca, Editorial Porrúa.

Castillo, Cristobal del. 2001. Historia de la venida de los mexicanos y de otros pueblos e historia de la conquista. Traducción y estudio introductorio de Federico Navarrete Linares. México: Consejo Nacional para la Cultura y las Artes.

Códice Borbónico. s.f. Codex Borbonicus. Original de la Bibliothèque de l'Assemblée nationale (Y 120). París.

Códice Borbónico. 1974 Codex Borbonicus. Facsímile. Codices Selecti XLIV. Graz: Akademische Druck- und Verlagsanstalt.

Códice Borgia. s.f. Original de la Biblioteca Apostólica Vaticana, núm. cat. Borg. Mess. 1. Ciudad del Vaticano. https://digi.vatlib.it/view/MSS_Borg.mess.1.

Códice Borgia. 1976. Codex Borgia. Facsímile. Codices Selecti LVIII. Graz: Akademische Druck- und Verlagsanstalt.

Códice Fejérváry-Mayer. Ver Anders et al. 1994.

Códice Florentino. 1979. Ver Sahagún.

Códice Mendoza. 1997. The Essential Codex Mendoza. Frances F. Berdan y Patricia Rieff Anawalt, eds. Berkeley, Los Angeles, Londres: University of California Press.

Códice Telleriano-Remensis. s.f. Original de la Biblioteca Nacional de Francia, núm. cat. 385 (Ant. 1), París. https://gallica.bnf.fr/ark:/12148/btv1b8458267s?rk=21459;2.

Códice Tudela. s.f. Códice Tudela o Códice del Museo de América. Original del Museo de América de Madrid.

Códice Vaticano B. s.f. Original de la Biblioteca Apostólica Vaticana, núm. cat. Vat. Lat. 3773. Ciudad del Vaticano. https://digi.vatlib.it/view/MSS_Vat.lat.3773.

Códice Vindobonensis. 1974. Codex Vindobonensis Mexicanus. Comentario de Otto Adelhofer. Serie Códices Selecti, vol. V. Graz: Akademische Druck- und Verlagsanstalt.

Códice Xolotl. s.f. Original de la Biblioteca Nacional de Francia, Fonds Mexicain, Collection Goupil-Aubin, Ms. 1-10. https://amoxcalli.org.mx/codice.php?id=001-010.

Craveri Slaviero, Michela. 2010. «Adivinación y pronósticos entre los mayas actuales». Arqueología Mexicana 103: 64-69.

-. 2013. Ver Popol Vuh.

Craveri, Michela y Rogelio Valencia. 2011. «The Voice of Writing: Orality Traces in the Maya Codices"», en Tradition and Innovation in Mesoamerican Cultural History. Roberto Cantú y Aaron Soonenschein, eds., pp. 77-113. Munich: Lincom Europa.

Dehouve, Danièle. 2009. «El lenguaje ritual de los mexicas: hacia un método de análisis», en Image and Ritual in the Aztec World: Selected Papers of the "Ritual Americas" Conferences, Sylvie Peperstraete, ed., pp. 19-33. BAR International Series 1896. Oxford: Archaeopress.

-. 2011. «Analogía y contigüidad en la plegaria indígena mesoamericana». Itinerarios 14: 153-184.

-. 2014. «Flores y tabaco, un difrasismo ritual». Revista Inclusiones. Homenaje a Miguel León-Portilla 1 (2): 9-28.

- 2019. "The "Law of the Series". A Proposal for the Decipherment of Aztec Ritual Language», en Indigenous Graphic Communication Systems. A Theoretical Approach, Katarzyna Mikulska y Jerome A. Offner, eds., pp. 95-122. Louisville: University Press of Colorado. 
Díaz Álvarez, Ana. 2015. «La pirámide, la falda, y una jicarita llena de maíz tostado. Una crítica a la representación de los niveles del cielo mesoamericanos», en Cielos e inframundos. Una revisión de las cosmologías mesoamericanas, Ana Díaz Álvarez, ed., pp. 65-107. México: Instituto de Investigaciones Históricas, Universidad Nacional Autónoma de México.

Durán, fray Diego. 1984. Historia de las Indias de la Nueva España e Islas de Tierra Firme. 2 vols. México: Editorial Porrúa.

Florentine Codex. 1950-1982. Ver Sahagún.

Furst, Jill Leslie. 1978. «The Year 1 Reed Alligator: A Mixtec Metaphor». Journal of Latin American Lore 4 (1): 93-128.

- 1982. «Skeletonization in Mixtec Art: A Re-evaluation», en The Art and Iconography of Late Post-Classic Central México. Conference at Dumbarton Oaks, Elizabeth Benson, ed., pp. 207-225. Washington D.C.: Dumbarton Oaks Research Library and Collections.

Gran Diccionario Náhuatl (GDN) [en línea]. Programa de Marc Thouvenot. http://www. sup-infor.com/dico/361/Dic_bnf_361.htm\#Español. http://www.sup-infor.com/dico/362/ Dic_bnf_362.htm\#Español.

Guilliem Arroyo, Salvador. 1998. «El Templo calendárico de México Tlatelolco».Arqueología Mexicana 34: 46-53.

Harris, Roy. 1999 (1995). Signos de escritura. Barcelona: Editorial Gedisa.

Hermann Lejarazu, Manuel. 2005. Códices y señoríos. Un análisis sobre los símbolos de poder en la Mixteca prehispánica. Tesis de Doctorado en Estudios Mesoamericanos, Facultad de Filosofía y Letras, Universidad Nacional Autónoma de México. 2 vols.

- 2008. «Rituals of Power in the Mixtec Codices». Latin American Indian Literatures Journal 24 (2): 125-150.

Hermann Lejarazu, Manuel y Krystyna M. Libura. 2007. La creacion del mundo según el Códice Vindobonensis, México: Secretaría de Educación Pública.

Historia de los mexicanos por sus pinturas. 2002. En Mitos e historias de los antiguos nahuas, Rafael Tena, ed., pp. 23-95. México: Consejo Nacional para la Cultura y las Artes.

Jansen, Maarten E.R.G.N. 1982. Huisi Tacu, estudio interpretativo de un libro mixteco antiguo: Codex Vindobonensis Mexicanus I. 2 vols. Amsterdam: Centro de Estudios y Documentación Latinoamericanos.

- 1985. «Las Lenguas Divinas del México Precolonial». Boletín de Estudios Latinoamericanos y del Caribe 38: 3-14.

-. 1988. «The Art of Writing in Ancient Mexico: An Ethno-Iconographical Perspective», en Visible Religion. Annual for Religious Iconography, Vol. 6: The Image in Writing, Hans G. Kippenberg, L. P. van den Bosch, L. Leertouwer y Hazel A. Witte, eds., pp. 86-113. Leiden: E. J. Brill.

- 2002. «Una mirada al interior del Templo de Cihuacóatl. Aspectos de la función religiosa de la escritura pictórica», en Libros y escritura de tradición indígena. Ensayos sobre los códices prehispánicos y coloniales de México, Carmen Arellano Hoffmann, Peer Schmidt y Xavier Noguez, eds., pp. 279-326. Toluca: Colegio Mexiquense, Universidad Católica de Eichstätt.

- 2012. «Ancient Mexican Books of Time: Interpretive Developments and Prospects». Analecta Praehistorica Leidensia 43/44: 77-94.

Jansen, Maarten E.R.G.N. y Aurora Pérez Jiménez. 2008. «Paisajes sagrados: códices y arqueología de Ñuu Dzaui». Itinerarios. Revista de estudios lingüísticos, literarios, históricos y antropológicos 8: 83-111. 
- 2009. «Lenguaje ceremonial en los códices mixtecos», en Image and Ritual in the Aztec World. Selected Papers of the "Ritual Americas" Conferences, Sylvie Peperstraete, ed., pp. 7-18. BAR International Series 1896. Oxford: Archeopress.

Köhler, Ulrich. 2001. "'Debt-payment' to the Gods among the Aztecs: the Misreading of a Spanish Expression and its Effects». Estudios de Cultura Náhuatl 32: 125-133.

Leroi-Gourhan, André. 1971. El gesto y la palabra. Caracas: Universidad Central de Venezuela. Leyenda de los Soles. 1992. En Codex Chimalpopoca. The Text in Nahuatl with a Glossary and Grammatical Notes, John Bierhorst, ed., pp. 85-100. Tucson, Londres: University of Arizona Press.

López Austin, Alfredo. 1967. «Términos del nahuallatolli». Historia Mexicana XVII: 1-36.

-. 1995. Tamoanchan y Tlalocan. México: Fondo de Cultura Económica.

López García, Ubaldo. 2007. Sa 'vi. Discursos ceremoniales de Yutsa To ’on (Apoala). Tesis de Doctorado. Universidad de Leiden.

Martínez Gracida, Araceli. 2012. El tiempo y la sabiduría en Poxoyëm. Un calendario sagrado entre los Ayook de Oaxaca. Tesis de Doctorado. Facultad de Arqueología, Universidad de Leiden.

Mendieta, fray Gerónimo de. 1993 (1870). Historia eclesiástica indiana. México: Editorial Porrúa.

Mikulska, Katarzyna. 2008. El lenguaje enmascarado. Un acercamiento a las representaciones gráficas de deidades nahuas. México: Instituto de Investigaciones Antropológicas, Universidad Nacional Autónoma de México y Sociedad Polaca de Estudios Latinoamericanos, Universidad de Varsovia.

-. 2010. «"Secret Language” in Oral and Graphic Form. Religious-magic Discourse in Aztec Speeches and Manuscripts». Oral Tradition 25 (2): 325-363.

- 2015a. Tejiendo destinos. Un acercamiento al sistema de comunicación gráfica en los códices adivinatorios. México: El Colegio Mexiquense e Instituto de Estudios Ibéricos e Iberoamericanos, Universidad de Varsovia.

- 2015b. «Los cielos, los rumbos y los números. Aportes sobre la visión indígena del universo», en Cielos e inframundos. Una revisión de las cosmologías mesoamericanas, Ana Díaz Álvarez, ed., pp. 109-173. México: Instituto de Investigaciones Históricas, Universidad Nacional Autónoma de México.

- 2017. «¿El dios en mosaico? La composición de la imagen de la deidad en los códices adivinatorios». Trace 71: 40-75.

- 2019. «The System of Graphic Communication in the Central Mexican Divinatory Codices from the Functional Perspective», en Indigenous Graphic Communication Systems. A Theoretical Approach, Katarzyna Mikulska y Jerome A. Offner, eds., pp. 41-92. Louisville: University Press of Colorado.

- 2020a. «Tres componentes de codificación en el sistema de comunicación gráfica de los códices Vaticano B y Borgià, en Nuevo comentario al Códice Vaticano B (Vat. Lat. 3773), Katarzyna Mikulska, ed., pp. 345-397. México: Instituto de Investigaciones Históricas, Universidad Nacional Autónoma de México, Instituto de Estudios Ibéricos e Iberoamericanos, Universidad de Varsovia, Biblioteca Apostólica Vaticana.

- 2020b. «Los dioses y sus nombres: el caso de los dioses solares», en Nuevo comentario al Códice Vaticano B (Vat. Lat. 3773), Katarzyna Mikulska, ed., pp. 509-555. México: Instituto de Investigaciones Históricas, Universidad Nacional Autónoma de México, Instituto de Estudios Ibéricos e Iberoamericanos, Universidad de Varsovia, Biblioteca Apostólica Vaticana.

Molina, fray Alonso de. 1980 (1571). Vocabulario en lengua castellana y mexicana y mexicana y castellana. México: Editorial Porrúa. 
Monaghan, John. 1990. «Performance and the Structure of the Mixtec Codices». Ancient Mesoamerica 1 (1): 133-140.

Montes de Oca Vega, Mercedes. 2013. Los difrasismos en el náhuatl de los siglos XVI y XVII. México: Instituto de Investigaciones Filológicas, Universidad Nacional Autónoma de México. http://www.iifilologicas.unam.mx/ebooks/los-difrasismos-en-el-nahuatl/.

Ms. Aubin No. 20. s.f. Original de la Biblioteca Nacional de Francia, Fonds Mexicain, Collection Goupil-Aubin, Ms. 20.

Nowotny, Karl Anton. 2005 (1961). Tlacuilolli: Style and Contents of the Mexican Pictorial Manuscripts with a Catalog of the Borgia Group. Trad. y ed. George A. Everett Junior y Edward B. Sisson; introd. Ferdinand Anders. Norman: University of Oklahoma Press.

Popol Vuh. 2013. Popol Vuh. Herramientas para una lectura crítica del texto k'iche'. Trad. al español, notas gramaticales y vocabulario de Michela E. Craveri. México: Instituto de Investigaciones Filológicas, Universidad Nacional Autónoma de México.

Proceso del Santo Oficio contra Mixcoatl y Papalotl, indios, por hechiceros. 1912. En Procesos de indios idólatras y hechiceros, edición y estudio preliminar de Luis González Obregón, pp. 53-78. México: Secretaría de Relaciones Exteriores, Publicaciones del Archivo General de la Nación III.

Reyes, fray Antonio de los. 1976 (1593). Arte en lengua mixteca. Edición facsimilar. Publications in Anthropology 14. Nashville: Vanderbilt University.

Ruiz de Alarcón, Hernando. 1953. «Tratado de las supersticiones y costumbres gentílicas que oy viuen entre los indios naturales de esta Nueva España», en Tratado de las idolatrías, supersticiones, dioses, ritos, hechicerías y otras costumbres gentílicas de las razas aborígenes de México, ed. de Francisco del Paso y Troncoso, Tomo 2, pp. 17-180. México: Ediciones Fuente Cultural.

Sahagún, fray Bernardino de. 1950-1982. Florentine Codex. General History of the Things of New Spain. Ed. y trad. de Arthur J. O. Anderson y Charles E. Dibble. Santa Fe: The School of American Research, University of Utah.

- 1979. Códice Florentino. El Manuscrito 218-220 de la Colección Palatina de la Biblioteca Medicea Laurenziana. Edición facsimilar. 3 vols. México: Archivo General de la Nación.

- 1989. Historia general de las Cosas de Nueva España. Ed. de Josefina García Quintana y Alfredo López Austin. 2 vols. México: Consejo Nacional para la Cultura y las Artes, Alianza Editorial Mexicana.

Sandstrom, Alan. 1991. Corn Is Our Blood. Culture and Ethnic Identity in a Contemporary Aztec Indian Village. Norman: University of Oklahoma Press.

Seler, Eduard. 1990-2000. Collected Works in Mesoamerican Linguistics and Archaeology (trad. de Gesammelte Abhandlungen zur Amerikanischen Sprach-und Alterthumskunde), edición de J. Eric S. Thompson, Charles P. Bowditch, Francis B. Richardson y Frank E. Comparato. 6 vols. Culver City: Labyrinthos.

Serna, fray Jacinto de la. 1987. «Manual de ministros de Indias (1656)», en El alma encantada. Anales del Museo Nacional de México, pp. 263-480. México: Instituto Nacional Indigenista, Fondo de Cultura Económica.

Tedlock, Dennis. 1983. «Las formas del verso quiché», en Nuevas perspectivas sobre el Popol Vuh, Robert Carmack y Francisco Morales Santos, eds., pp. 123-132. Guatemala: Editorial Piedra Santa.

Thouvenot, Marc. 2010. «Imagen y escritura entre los nahuas del inicio del XVI». Estudios de Cultura Náhuatl 41: 167-191.

Zumthor, Paul. 1986. «Właściwości tekstu oralnego» (Las propiedades del texto oral) Literatura Ludowa 1 (XXX): 41-58. 